\title{
$B C L-X L$ is essential for the protection from secondary anemia caused by radiation-induced fatal kidney damage
}

Kerstin Brinkmann ${ }^{1,2^{*}}$, Paul Waring ${ }^{4}$, Stefan Glaser $^{1,2,3}$, Verena Wimmer ${ }^{1,2}$, Duong Nhu ${ }^{1,2}$, Lachlan Whitehead $^{1,2}$, Alex RD Delbridge ${ }^{1,2,5}$, Guillaume Lessene ${ }^{1,2}$, Marco J Herold ${ }^{1,2}$, Gemma L Kelly , $^{1,2}$ Stephanie Grabow ${ }^{1,2,6, \#}$, Andreas Strasser ${ }^{1,2, \# *}$

${ }^{1}$ The Walter and Eliza Hall Institute of Medical Research, Melbourne, Australia

${ }^{2}$ Department of Medical Biology, University of Melbourne, Melbourne, Australia

${ }^{3}$ current address: Boehringer Ingelheim RCV GmbH \& Co KG, Vienna, Austria

${ }^{4}$ Department of Surgery, University of Melbourne, Melbourne, Australia

${ }^{5}$ current address: Putnam Associates, Boston, MA, United States

${ }^{6}$ current address: Blueprint Medicines, Cambridge, MA, United States

\# these authors share senior authorship

*To whom correspondence should be addressed at:

Andreas Strasser, The Walter and Eliza Hall Institute of Medical Research, Melbourne, VIC 3052, Australia, strasser@wehi.edu.au

Kerstin Brinkmann, The Walter and Eliza Hall Institute of Medical Research, Melbourne, VIC 3052, Australia, brinkmann.k@wehi.edu.au

Running title: BCL-XL protects from secondary anemia 


\section{Summary:}

The inducible loss of BCL-XL in all cells of adult mice causes primary anemia due to apoptosis of erythroid and megakaryocytic cell populations. In contrast $\gamma$-radiation plus loss of BCL-XL in all cells except hematopoietic cells causes secondary anemia resulting from kidney damage.

\footnotetext{
Abstract

Studies of gene-targeted mice identified the roles of the different pro-survival BCL-2 proteins during embryogenesis, but less is known about the roles of these proteins in adults, including in the response to cytotoxic stresses, such as treatment with anti-cancer agents. We investigated the role of $\mathrm{BCL}-\mathrm{XL}$ in adult mice using a strategy where prior bone marrow transplantation allowed for loss of BCL-XL exclusively in non-hematopoietic tissues to prevent anemia caused by BCLXL-deficiency in erythroid cells. Unexpectedly, the combination of total-body $\gamma$-irradiation (TBI) and genetic loss of $\mathrm{Bcl}-\mathrm{x}$ caused secondary anemia resulting from chronic renal failure due to apoptosis of renal tubular epithelium with secondary obstructive nephropathy. These findings identify a critical protective role of $B C L-X L$ in the adult kidney and inform on the use of BCL-XL inhibitors in combinations with DNA damage-inducing drugs for cancer therapy.
} 


\section{Introduction}

Evasion of apoptotic cell death is a hallmark of cancer (Hanahan and Weinberg, 2000; Hanahan and Weinberg, 2011) and direct activation of the cell death machinery by BH3-mimetic drugs represents an attractive therapeutic strategy (Merino et al., 2018). Apoptosis is controlled by proand anti-apoptotic members of the BCL-2 protein family (Tait and Green, 2010), with the transcriptional or post-transcriptional activation of the pro-apoptotic BH3-only members of the BCL-2 family (e.g. BIM, PUMA) being its initiator. They bind with high affinity to the anti-apoptotic BCL-2 family members (e.g. BCL-2, BCL-XL), thereby unleashing the pro-apoptotic effector proteins $\mathrm{BAX}$ and BAK to cause mitochondrial outer membrane permeabilization (MOMP). MOMP causes the release of activators of the caspase cascade that causes cell demolition (Riedl and Salvesen, 2007; Tait and Green, 2010). The extent of MOMP and apoptosis are considered key determinants of therapeutic success of anti-cancer therapeutics (Del Gaizo Moore and Letai, 2013). BH3-only proteins, particularly PUMA (Villunger et al., 2003) and BIM (Bouillet et al., 1999a), are critical for the killing of malignant (and non-transformed) cells by diverse anti-cancer agents. As a consequence of genetic or epigenetic changes, many cancers show a reduction in pro-apoptotic BH3-only proteins or over-expression of pro-survival BCL-2 proteins (Beroukhim et al., 2010; Uhlen et al., 2005; Uhlen et al., 2017). Certain cancer cells can be killed by the loss of a single pro-survival BCL-2 family member (Glaser et al., 2012; Kelly et al., 2014), whereas others require loss/inhibition of two or more of these proteins (Campbell and Tait, 2018). Several smallmolecule inhibitors of pro-survival BCL-2 proteins (BH3-mimetic drugs) have been developed (Adams and Cory, 2018). Even though BH3-mimetics can potently kill diverse cancer cells in vitro and in vivo, the safe clinical use of some of these drugs remains challenging due to the obligate roles of pro-survival BCL-2 proteins for the survival of normal cells in healthy tissues (Adams and Cory, 2018).

Gene deletion studies in mice have helped identify the critical roles of the different pro-survival BCL-2 family members. Loss of A1/BFL-1 causes minor reductions in certain hematopoietic cell 
subsets (Schenk et al., 2017; Tuzlak et al., 2017) and loss of BCL-W causes male sterility (Print et al., 1998). BCL-2-deficient mice die soon after weaning due to polycystic kidney disease and also present with reductions in mature B as well as $\mathrm{T}$ lymphocytes and melanocytes (causing premature greying) (Veis et al., 1993). These abnormalities could be prevented by concomitant loss of pro-apoptotic BIM (Bouillet et al., 2001). Constitutive loss of MCL-1 causes embryonic lethality prior to implantation (E3.5) (Rinkenberger et al., 2000) and tissue-restricted deletion revealed that many cell types, including cardiomyocytes (Thomas et al., 2013; Wang et al., 2013), neurons (Arbour et al., 2008) and several hematopoietic cell subsets (Opferman et al., 2005) require MCL-1 for survival. Loss of $B c l-x$ causes embryonic lethality at $\sim \mathrm{E} 13.5$ with aberrant death of neurons and immature hematopoietic cells (Motoyama et al., 1995). Conditional deletion of $B c /-$ $x$ in erythroid cells causes fatal anemia (Wagner et al., 2000) and loss of just one allele of $B c l-x$ impairs male fertility (Rucker et al., 2000) and reduces platelet numbers (Mason et al., 2007).

BH3-mimetic drugs that selectively target BCL-XL (A1331852) (Lessene et al., 2013) or BCL-2 (ABT-199) (Souers et al., 2013) or compounds that inhibit BCL-XL, BCL-2 and BCL-W (ABT-737, ABT-263) (Oltersdorf et al., 2005; Tse et al., 2008) have been developed. Even though inhibitors of BCL-XL can efficiently kill diverse cancer cells, by themselves or in combination with additional anti-cancer agents (Cragg et al., 2008; Cragg et al., 2007; Oltersdorf et al., 2005; Tse et al., 2008), these compounds are progressing slowly in the clinic. This is in part due to the fact that the essential roles of BCL-XL in the adult (beyond its role in hematopoietic cells) are not clearly understood. Here we investigated the impact of inducible loss of BCL-XL in adult mice. This revealed that $B C L-X L$ loss is tolerated throughout the body as long as the hematopoietic cells remain BCL-XL-sufficient. However, mice that had been $\gamma$-irradiated (for hematopoietic transplantation) and then subjected to loss of BCL-XL developed secondary anemia due to chronic renal failure characterized by renal tubular epithelial cell apoptosis with secondary obstructive nephropathy. This morbidity could be markedly delayed, although not abrogated, by the concomitant loss of pro-apoptotic PUMA or BIM. These findings predict potential toxicities and 
their underlying mechanisms resulting from combinations of BCL-XL inhibitors with DNA damageinducing anti-cancer therapeutics.

\section{Results}

\section{Impact of induced deletion of BCL-XL in adult mice}

$B c /-x^{-/-}$embryos die $\sim$ E13.5 due to loss of neuronal and erythroid cells (Motoyama et al., 1995).

Mice with hypo-morphic mutations in the $B c l-x$ gene are viable but develop severe thrombocytopenia and anemia (Mason et al., 2007). We wanted to explore the consequences of inducible loss of BCL-XL in adult mice. For this, we crossed $B c l-x^{f / f l}$ mice with RosaCreERT2 mice that express a CreERT2 fusion protein in all tissues. CreERT2 is normally kept inactive in the cytoplasm by binding to HSP90 but can be activated by tamoxifen (Vooijs et al., 2001). Even though BCL-XL is essential for neuronal cell survival (Motoyama et al., 1995), we did not expect any neuronal abnormalities upon tamoxifen-treatment in $B c /-x^{f / f f l} ; R o s a C r e E R T 2^{+/ K i}$ mice since tamoxifen administered by oral gavage did not efficiently drive CreERT2-mediated deletion of the $B c l-x$-floxed genes in the brain, as shown by Southern blotting (Supplementary Figure S1A). Almost complete deletion of the $B c l-x$ gene was achieved in most other tissues, including the spleen, kidney, liver, pancreas, intestine and lung, whereas deletion in the testis was $\sim 70 \%$.

As reported (Motoyama et al., 1995; Wagner et al., 2000), we found that induced loss of BCL-XL in adult mice caused fatal thrombocytopenia and anemia with a median survival of $\sim 25$ days (Figure 1A). Accordingly, the BCL-XL-deleted mice presented with significant decreases in platelets, red blood cells (RBCs), hemoglobin content (HGB) and hematocrit (HCT) (Figures 1CF), accompanied by massively enlarged spleens due to compensatory erythropoiesis (Figure 1GI).

To identify the essential functions of BCL-XL in non-hematopoietic tissues of adult mice we generated bone marrow chimeras: $B c /-x^{f / f f l} ; R o s a C r e E R T 2^{+/ K i}$ mice that had been lethally irradiated and reconstituted with wild-type bone marrow cells from UBC-GFP mice (GFP-Chimeras; 
experimental design in Supplementary Figure S1B). Unexpectedly, these animals also presented with severe anemia and thrombocytopenia after loss of BCL-XL, albeit at a considerably later time (Figure 1C-F). Around day 100 post-treatment with tamoxifen, the $\mathrm{Bcl}-\mathrm{x}^{\mathrm{fl/fl} ;} ;$ RosaCreERT2 $^{+/ K i} ; \mathrm{GFP}$ Chimeras appeared runty, lethargic and anemic and were sacrificed after $>15 \%$ body weight loss (median survival $=102$ days, Figures 1B). Notably, sick Bcl- $x^{f / / f l} ; R_{0 s a C r e E R T 2^{+/ K i} ; G F P-C h i m e r a s}$ did not present with splenomegaly (Figure 1G) or an increase in the red pulp area of the spleen (Figure 1I), which are hallmarks of primary anemia caused by loss of BCL-XL in erythroid and megakaryocytic cell populations (Figure 1G-I). Importantly, the tamoxifen-treated $B c /-x^{f / f f l} ; G F P$ Chimera and RosaCreERT2 ${ }^{+/ K i} ;$ GFP-Chimera control mice all survived without any adverse events for $>240$ days (termination of the experiment).

These findings demonstrate that inducible loss of BCL-XL in all tissues of adult mice (including hematopoietic cells) causes primary anemia and thrombocytopenia, whereas the combination of total body $\gamma$-irradiation (TBI), followed by rescue with a UBC-GFP hematopoietic system, and inducible loss of BCL-XL only in non-hematopoietic cells causes secondary anemia.

The secondary anemia in mice caused by the combination of $\gamma$-radiation and inducible deletion of BCL-XL is not driven by inflammation, hematopoietic malignancy or liver damage

TBI is commonly used for the treatment of hematological malignancies, often alongside with high dose chemotherapy, prior to hematopoietic stem/progenitor cell (HSPC) transplantion. TBI causes many side-effects, including nausea, diarrhoea, sensitive skin and hair loss, that are temporary. However, TBI can also cause severe long-term damage to several organs, such as the lung, trachea and mouth (radiation-induced pneumonitis, fibrosis, oral mucositis) (Marks et al., 2003; Mehta, 2005), reproductive system (radiation-induced infertility) (Ogilvy-Stuart and Shalet, 1993), liver (radiation-induced liver disease) (Kim and Jung, 2017), gastro-intestinal tract 
(radiation-induced gastric mucositis, radiation-induced gastro intestinal syndrome) (Francois et al., 2013; Olcina and Giaccia, 2016) or kidney (radiation-induced nephropathy) (Cohen, 2000; Cohen and Robbins, 2003). Furthermore, TBI can also initiate secondary malignancies (Dracham et al., 2018).

The above-mentioned TBI-induced pathologies frequently cause secondary anemia (Davis and Littlewood, 2012; Weiss and Goodnough, 2005). For example, hematological malignancies impair the production of RBCs in the bone marrow as a consequence of competing for essential growth factors, the production of reactive oxygen species (ROS) and pro-inflammatory cytokines that damage erythroid progenitors (Davis and Littlewood, 2012; Weiss and Goodnough, 2005). Moreover, a robust inflammatory response is observed upon radiation-induced damage to the gastro-intestinal tract (Olcina and Giaccia, 2016). Pro-inflammatory cytokines (e.g. IL-6, TNF $\alpha$ ) interfere with the production of erythropoietin (EPO) and the availability of iron, both crucial for RBC development. Furthermore, inflammatory cytokines enhance the production of white blood cells (WBCs) and can thereby decrease the differentiation of progenitors into RBCs (Weiss and Goodnough, 2005). We did not detect signs of ongoing inflammation as shown by the observation that the numbers of WBCs (Figure 2A), including lymphocytes, neutrophils, basophils, eosinophils and monocytes, were all within the normal range (Supplementary Figure S2A). The neutrophil to lymphocyte ratio (NLR), even though increased in the tamoxifen-treated $\mathrm{Bcl}$ $x^{f|f| f l} ;$ RosaCreERT2 $2^{+/ K i} ;$ GFP-Chimeras, was still within the normal range (Figure 2B). Moreover, no signs of hematological malignancies, such as increased numbers of leukocytes were observed in the blood or bone marrow of the tamoxifen-treated $B c l-x^{f l / f l} ;$ RosaCreERT2 ${ }^{+/ K i} ; G F P-C h i m e r a s$ (Figure 2A and C).

The liver represents the primary storage site of iron and source of hepcidin, both essential for RBC-production. Hence, secondary anemia can result from liver damage. Histological analysis failed to reveal any abnormalities in the livers of the tamoxifen-treated $\mathrm{Bcl}$ $x^{f / f f l} ;$ RosaCreERT2 ${ }^{+/ K i} ;$ GFP-Chimeras (Figure 2D) and no marked increases in the liver enzyme 
ALT or unconjugated bilirubin were detected in their sera (Figure 2E). However, these animals presented with increased levels of AST (Figure 2E), but unlike ALT, AST is also found in the heart, skeletal muscle, kidney and RBCs. Thus, with the lack of other indicators of liver pathology, we attributed this AST-increase to non-liver toxicity.

These findings demonstrate that the secondary anemia in the tamoxifen-treated $\mathrm{Bcl}$ $x^{f / f f l} ;$ RosaCreERT2 $2^{+/ K i} ;$ GFP-Chimeras is not a consequence of erythroid cell destruction, hematologic malignancy, chronic infection, inflammation nor liver damage. Instead, these results suggest that the secondary anemia might be caused by radiation-induced kidney damage.

\section{The combination of $\gamma$-radiation and inducible deletion of BCL-XL causes severe kidney damage in adult mice}

EPO stimulates erythropoiesis and is produced in response to cellular hypoxia in the kidney by interstitial fibroblasts adjacent to the renal proximal convoluted tubule and peritubular capillaries. Acute and chronic kidney disease that damage these cells decreases the production of EPO, thereby compromising the generation of erythroid progenitors (CFU-e) and thus RBC-production. We hypothesized that the secondary anemia observed in tamoxifen-treated Bcl$x^{f / f f l} ;$ RosaCreERT2 $2^{+/ K i} ;$ GFP-Chimeras results from damage to the EPO-secreting cells in the kidney. Accordingly, urine tests showed severe proteinuria in sick tamoxifen-treated $\mathrm{Bcl}$ $x^{f / / f l} ;$ RosaCreERT2 $2^{+/ K i} ;$ GFP-Chimeras (Supplementary Figure S2F) and due to increased urination the bedding of their cages had to be changed frequently.

The kidneys of these sick mice were abnormally small and yellow (Figure $3 \mathrm{~A}$ and B). Histological analysis revealed severe renal tubulo-interstitial disease with segmental areas showing diminution of the renal tubules, interstitial fibrosis and patchy chronic inflammation with focal and segmental glomerular changes and thickening of renal arterioles. The renal medulla and papillae contained intraluminal calcified cellular debris and crystalline precipitates within the collecting ducts and dilated loops of Henle, where urine is concentrated (Figure 3C). This was sometimes 
accompanied by intraluminal multinucleated macrophages, reminiscent of the changes seen in myeloma nephropathy. The glomeruli in the affected segments showed secondary focal and segmental sclerosis. These structural changes were additionally visualized using confocal microscopy (Supplementary Figure S3).

The kidney damage was confirmed using multiphoton microscopy (Figure 3D). To avoid spurious signals due to non-specific antibody binding, the kidneys were visualized using short wavelength auto-fluorescence (blue) and second harmony generation (SHG) (green). Materials that efficiently generate SHG include type-1-collagen, myosin, tubulin or non-linear crystals and minerals. Intensity of short wavelength auto-fluorescence provides information on the metabolic activity as it visualizes metabolic co-factors, including NADH and NADPH. Accordingly, higher short wavelength auto-fluorescence was observed in the mitochondria-rich proximal tubular cells compared to the distal tubular cells in the kidneys from healthy control mice. In contrast, a significant reduction in metabolically active cells was observed in the atrophic segmental areas in sick mice (Figure 3D). The above-mentioned precipitates within the dilated loops of Henle generated a strong SHG signal, confirming their crystalline nature (Figure 3D).

These findings demonstrate that the combination of TBI and $B c l-x$-deletion cause fatal renal tubulo-interstitial disease.

\section{The combination of $\gamma$-radiation and inducible deletion of BCL-XL causes apoptosis of}

\section{tubular epithelial cells in the kidney}

Loss or inhibition of pro-survival BCL-XL causes apoptotic cell death (Adams and Cory, 2007). We therefore performed TUNEL staining that detects 3'-hydroxyl termini in double-strand DNA breaks, a hallmark of apoptotic cells (Gavrieli et al., 1992; Gorczyca et al., 1992), to determine whether inducible loss of BCL-XL, TBI or their combination caused apoptosis in renal cells. We observed significantly increased numbers of TUNEL ${ }^{+}$cells in kidney sections from sick tamoxifentreated $\mathrm{Bcl}-x^{f / f f l} ;$ RosaCreERT2 ${ }^{+/ K i} ;$ GFP-Chimeras; they were mainly localized in the proximal 
tubular epithelium within segments showing tubulo-interstitial disease. In contrast, only occasional apoptotic cells were found in sections from control animals (Figure 4A and B).

Notably, 24 h following tamoxifen-treatment (8 weeks post-TBI), TUNEL ${ }^{+}$cells were detected in $\mathrm{BCl} x^{f / f f l} ;$ RosaCreERT2 ${ }^{+/ K i} ;$ GFP-Chimeras as well as in control RosaCreERT2 ${ }^{+/ K i} ;$ GFP-Chimeras, $\mathrm{Bcl}-x^{f / / f l} ;$ RosaCreERT2 ${ }^{+/ K i}$ and RosaCreERT2 ${ }^{+/ K i}$ mice (Figure $4 \mathrm{~A}$ and $\mathrm{B}$ ). This indicates that both TBI and loss of BCL-XL by themselves induce renal tubular epithelial cell apoptosis. However, in contrast to the control mice that were able to recover from TBI-induced kidney damage, the additional loss of BCL-XL resulted in more extensive apoptosis in the renal tubular epithelium with their cellular debris accumulating in the renal loops of Henle and collecting ducts. This caused secondary obstruction, glomerulopathy and interstitial nephropathy with damage to the adjacent EPO-secreting peritubular interstitial cells.

These findings demonstrate that the combination of TBI and inducible loss of BCL-XL causes extensive apoptosis in the renal proximal convoluted tubular epithelium, leading to chronic renal failure and secondary anemia.

\section{Concomitant loss of BIM or PUMA delays kidney disease with secondary anemia caused by radiation and the induced loss of $B C L-X L$ in adult mice}

We next investigated which $\mathrm{BH} 3$-only protein was critical for apoptosis in the renal tubular epithelium. We focused on BIM and PUMA because both play critical roles in DNA damageinduced apoptosis in diverse cell types (Bouillet et al., 1999a; Erlacher et al., 2005; Villunger et al., 2003). We observed a significant extension of survival of tamoxifen-treated $\mathrm{Bcl}$ $x^{f / f f l} ;$ RosaCreERT2 $2^{+/ K_{i} ; B^{+/-} ; G F P-C h i m e r a s}$ (median survival 159 days; $\quad$ p<0.0001), Bcl-

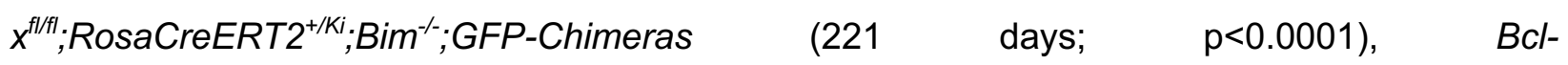

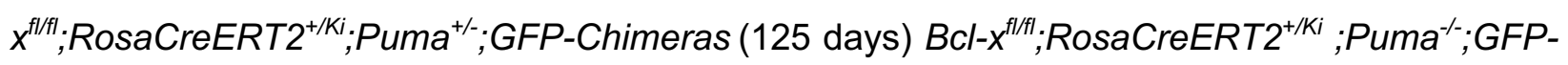
Chimeras (281 days; $p<0.0001)$ compared to the $B c /-x^{f / f f l} ;$ RosaCreERT2 ${ }^{+/ K i} ; G F P$-Chimeras (102 days) (Figure 5A,B). Combined loss of one allele of Bim plus one allele of Puma (Bcl- 
$x^{f / f f l} ;$ RosaCreERT2 ${ }^{+/ K i} ;$ Bim $^{+/-;} ;$Puma ${ }^{+/-; G F P-C h i m e r a s) ~ r e s u l t e d ~ i n ~ a ~ s i m i l a r ~ e x t e n s i o n ~ o f ~ l i f e s p a n ~ a s ~}$ seen for mice lacking either both alleles of Bim or both alleles of Puma (median survival 243 days; $p<0.0001$ ) (Figure 5A,B). Nevertheless, all these mice ultimately presented with similar pathology as the tamoxifen-treated $B c /-x^{f / / f l} ;$ RosaCreERT2 ${ }^{+/ K i} ; G F P$-Chimeras, including kidney damage (Figure 5C) and secondary anemia (Figure 5D-F).

These results demonstrate that BIM and PUMA play critical overlapping roles in the induction of apoptosis of renal tubular epithelial cells.

\section{Pharmacological inhibition of BCL-XL in combination with DNA-damaging anti-cancer therapeutics does not cause kidney disease with secondary anemia}

BH3 mimetic drugs targeting select anti-apoptotic BCL-2-family members represent promising novel agents in cancer therapy (Merino et al., 2018). The BCL-XL-specific inhibitor A1331852 (Lessene et al., 2013) has not yet entered clinical trials, mostly due to its on-target toxicity in platelets that is also seen with ABT-263/navitoclax that inhibits BCL-XL, BCL-2 and BCL-W (Leverson et al., 2015; Mason et al., 2007; Wilson et al., 2010). Nevertheless, many cancers depend on BCL-XL for sustained growth (Campbell and Tait, 2018; Merino et al., 2018) and extensive work is being conducted to develop modes of administration and dose schedules for the safe use of BCL-XL inhibitors (Khan et al., 2019). Our present data indicate that the combination of BCL-XL inhibitors with DNA damage-inducing therapies might cause renal toxicity with secondary anemia. However, drug-mediated inhibition of a pro-survival BCL-2 family member often exerts considerably less severe impact than genetic loss of this protein, as demonstrated for MCL-1 (Kotschy et al., 2016). Thus, in contrast to the genetic deletion of Bcl-x resulting in a permanent loss of BCL-XL protein, the pharmacological inhibition of $B C L-X L$ for a defined period might be tolerated, even in combination with DNA damage-inducing chemotherapeutics. To test this hypothesis, we treated wild-type mice that had been $\gamma$-irradiated and reconstituted with UBCGFP bone marrow with a clinically relevant and well-tolerated dose of the BCL-XL inhibitor 
A1331852 (Leverson et al., 2015). Additionally, we treated wild-type mice with a combination of clinically relevant and well-tolerated doses of either of the DNA-damaging drugs 5-Fluorouracil (5-FU) or Cyclophosphamide plus A1331852. No adverse effects of any of these treatments were detected for at least 150 days (Figure 6A, B). As expected (Leverson et al., 2015; Mason et al., 2007; Merino et al., 2018; Wilson et al., 2010), treatment with A1331852 resulted in on-target platelet toxicity at day 2 post-treatment, followed by high platelet counts at days 5-6 post treatment (Figure $6 \mathrm{C}, \mathrm{G}$ ). All mice recovered within $\sim 10$ days (Figure $6 \mathrm{C}$ ). This is consistent with the described BCL-XL-dependency of platelets and thus platelet toxicity followed by the rapid induction of a rebound production of platelets upon treatment with $\mathrm{BCL}-\mathrm{XL}$-inhibiting $\mathrm{BH} 3$ mimetic drugs (Leverson et al., 2015; Mason et al., 2007; Merino et al., 2018; Wilson et al., 2010). As reported (Brinkmann et al., 2017), treatment with 5-FU caused mild anemia (Figure 6E), and mice that were treated with Cyclophosphamide showed a reduction in lymphocytes at day 6 posttreatment (Supplementary Figure S5D). Importantly, for all drug-treated mice, the numbers of RBCs, platelets as well as HGB and HCT values and WBC counts were all in the normal range at the termination of the experiment (Figure 6D and E and Supplementary Figure S4B and D). The GFP-Chimeras were slightly lighter and had smaller kidneys and spleens at the end of the experiment (Figure 7A and Supplementary Figure S4A). However, urine testing (at 10 and 100 days post-treatment) did not provide evidence of kidney damage (data not shown). No significant differences in the weights of the kidneys or spleens were observed between mice that were treated with DNA-damaging chemotherapy (5-FU or Cyclophosphamide) alone or in combination with A1331852 when compared to untreated mice (Figure 7B). Histological analysis revealed normal architecture of the kidneys (Figure $7 \mathrm{C}, \mathrm{D}$ ), liver, spleen and bone marrow in all experimental and control mice (Supplementary Figure S5).

These results show that the combination of DNA damage-inducing anti-cancer therapy plus a BCL-XL inhibitor can be tolerated, at least when used sequentially. 


\section{Discussion}

TBI and DNA damage-inducing drugs are current mainstays of cancer therapy. Apart from inducing the death of malignant cells, these treatments can also cause damage to diverse healthy tissues, including the kidney, with the underlying mechanisms still not well understood. In mice that received $\mathrm{TBI}$ prior to bone marrow transplantion, we found that genetic deletion of $\mathrm{BCL}-\mathrm{XL}$ exclusively in non-hematopoietic cells resulted in secondary anemia due to kidney damage. This could be substantially delayed by the concomitant loss of pro-apoptotic PUMA or BIM. This reveals that in the context of DNA damage, $B C L-X L$ is critical for the sustained survival of renal tubular epithelial cells in the adult. Notably, BCL-2 loss results in severe polycystic kidney disease that starts during embryonic development (in the absence of DNA damage)(Bouillet et al., 2001; Veis et al., 1993). This indicates that BCL-2 and BCL-XL are both required to maintain renal tubule epithelial cell survival, the former during development and the latter in adulthood.

Radiation-induced nephropathy (RN) is frequently observed in cancer patients receiving $\mathrm{TBI}$ and bone marrow transplants (10-25\%)(Cohen, 2000; Cohen et al., 2010) (Cohen and Robbins, 2003). Interestingly, only some TBI-patients develop renal injury/failure, and the reasons for this are currently unknown (Cohen and Robbins, 2003). Our findings suggest that BCL-XL is essential to ensure the survival of renal cells that had previously sustained DNA damage, whereas undamaged cells can tolerate the loss of BCL-XL. The reasons for this could be that undamaged cells might express higher levels of pro-survival BCL-2 family members other than BCL-XL (e.g. BCL-2, MCL-1) or that damaged cells express higher levels of pro-apoptotic BH3-only proteins (Campbell and Tait, 2018; Merino et al., 2018). This hypothesis is supported by our demonstration that the concomitant loss of the BH3-only proteins BIM or PUMA can markedly delay kidney damage and secondary anemia caused by the combination of TBI and inducible loss of BCL-XL. Perhaps patients susceptible to $\mathrm{RN}$ express higher basal levels of $\mathrm{BH}$-only proteins in renal tissues, possibly because they are subject to certain stresses already. Alternatively, these cells 
may express abnormally low levels of pro-survival BCL-2 family members, possibly because they receive lower levels of growth factors (e.g. EGF, FGF).

All structures of the kidney can be affected by RN, including blood vessels, glomeruli, tubular epithelia and the interstitium (Cohen and Robbins, 2003). Our histological analysis indicates that the primary pathology is apoptosis of the proximal renal tubular epithelium rather than endothelial or glomerular damage. Proximal renal tubular epithelium cells are particularly rich in mitochondria and subject to stress due to their constant $\mathrm{H}^{+}$-pumping. This might render these cells prone to the induction of apoptosis driven by DNA-damage and the loss of BCL-XL. The deposits within the renal papillae are likely due to the accumulation of apoptotic debris and precipitates from concentrated urine in the loops of Henle or collecting ducts. These secondary obstructive changes are likely to have caused the chronic renal failure (consistent with the observed polyuria) and the segmental cortical scarring and glomerular changes (consistent with proteinuria). The glomerular changes are most likely a secondary effect and not directly caused by TBI as they were not seen in the control RosaCreERT2 $2^{+/ K i} ;$ GFP-Chimeras.

Besides TBI, genotoxic (e.g. cisplatin, cytarabine) as well as non-genotoxic drugs (e.g. cyclosporin, methotrexate) can induce kidney damage. With the advent of BH3-mimetic drugs for cancer therapy (Merino et al., 2018), it is important to understand what toxicities might arise from their combination with TBI or standard chemotherapeutics. We found that combinations of the BCL-XL-specific BH3-mimetic A1331852 with TBI, 5-FU or cyclophosphamide were tolerable in mice, at least when used sequentially. This reveals that genetic irreversible loss of $B c l-x$ has more severe consequences than pharmacological inhibition of $B C L-X L$ for a defined period. This conclusion is reminiscent of the findings from investigations comparing the impact of genetic loss of pro-survival MCL-1 vs treatment of mice for a defined period with an MCL-1 specific BH3mimetic drug (Caenepeel et al., 2018; Kotschy et al., 2016). These and other studies (Brennan et al., 2018; Brinkmann et al., 2017) suggest that it may be possible to establish therapeutic windows for combination treatment using $\mathrm{BH} 3-$ mimetic drugs and standard chemotherapy or radiation. 


\section{Materials and Methods}

\section{Mice}

$B c / x^{f l}$ (Wagner et al., 2000), Bim-- (Bouillet et al., 1999b), Puma ${ }^{-/-}$(Villunger et al., 2003), UBCGFP Tg (Schaefer et al., 2001) and RosaCreERT2 (Seibler et al., 2003) mice have been described. All mice were either generated on a C57BL/6 background or had been backcrossed onto this background for at least 20 generations. All experiments with mice were conducted according to the guidelines of The Walter and Eliza Hall Institute of Medical Research Animal Ethics Committee.

\section{Generation of bone marrow chimeras}

Recipient mice were subjected to 2 doses of 5.5 Gy given $3 \mathrm{~h}$ apart. After $2 \mathrm{~h}$, mice were transplanted with $3-6 \times 10^{6}$ UBC-GFP $\mathrm{Tg}$ bone marrow cells. Successful hematopoietic reconstitution was verified by detecting GFP+ blood cells by FACS.

\section{Chemotherapeutic drug treatment}

To activate CreERT2, mice were given $60 \mathrm{mg} / \mathrm{kg}$ tamoxifen (Sigma-Aldrich) in peanut oil/10\% ethanol for 3 days by oral gavage 8 weeks post-transplantation. The BCL-XL inhibitor A1331852 was synthesized in house, dissolved in 60\% Phosal PG 50, 27.5\% polyethylene glycol 400 (PEG400), $10 \%$ ethanol, $2.5 \%$ DMSO and administered by oral gavage. Working solutions of 5 Fluorouracil and Cyclophosphamide (Sigma- Aldrich) were prepared according to the manufacturer's instructions and a maximum volume of $200 \mu \mathrm{L}$ was injected into the tail vein (i.v.).

\section{Serum analysis}

Sera were stored at $-20^{\circ} \mathrm{C}$ and analyzed using Architect c1600 (Abbott Diagnostics,). 


\section{Histology}

Tissues were harvested and fixed in $10 \%$ formalin. Sections $(75 \mu \mathrm{m})$ were stained with hematoxylin and eosin (H\&E) and examined blinded to the genotype and treatment.

\section{TUNEL staining}

TUNEL staining was performed as described (Salvamoser et al., 2019). Slides were scored by microscopy in a blinded manner. Kidney sections were divided in $\sim 40$ microscopic images and the percentage of blue (TUNEL ${ }^{+}$) vs brown nuclei was determined using a personalized script for ImageJ. Data points represent average values for each kidney section.

\section{Microscopy}

For multiphoton microscopy kidneys were fixed in $4 \%$ paraformaldehyde overnight at $4{ }^{\circ} \mathrm{C}$ and embedded in 3\% low-melting point agarose (Sigma- Aldrich). Sections (500 $\mu \mathrm{M})$ were mounted on slides in glycerol. Images were acquired on an Olympus FVMPE-RS Multiphoton system (25x magnification, FV315/5W, NA 1.05, H2O, RT) equipped with a Mai-Tai eHP DeepSee multiphoton laser and processed using CellSens software (Olympus).

For confocal imaging, kidneys were fixed in $10 \%$ formalin. Sections $(75 \mu \mathrm{m})$ were mounted on adherent microscopic slides (Sarstedt). Slides were blocked in $2 \%$ normal donkey serum, $1 \%$ TritonX100 in PBS for 20 min at RT and stained overnight with rat-anti-PECAM1/CD31 antibodies (1/100, clone Mec13.3, BD Pharmingen) in blocking solution and secondary Alexa594 goat antirat IgG antibodies and DAPI (Invitrogen) in blocking solution for $1 \mathrm{~h}$. Slides were coverslipped with ProLong mounting media (Molecular Probes, Invitrogen) and imaged using a Zeiss LSM780 (25x magnicfication, oil, NA 0.8, RT).

\section{Statistical analysis}


Data were plotted and analyzed with Prism (GraphPad Software Inc). Statistical comparisons were conducted using unpaired two-tailed Student's t test assuming equal variance or one-way ANOVA analysis with Tukey's multiple comparisons test as indicated. N-numbers for individual experiments are provided in the figure legends.

\section{Author contributions}

$\mathrm{KB}, \mathrm{SGr}, \mathrm{SGI}$ and $\mathrm{AS}$ designed the study. MJH helped with the design of experiments. $\mathrm{KB}$ conducted all experiments. PW performed pathological analysis of tissue specimens; AD and GK helped with some experiments. VW helped with the multi-photon microscopic analysis. LW performed the quantification of the TUNEL assays. KB, PW and AS wrote the manuscript and all other authors edited it.

\section{Acknowledgments}

We thank Drs P Bouillet, JM Adams, L Hennighausen, and A Villunger for gifts of mice; T. Kitson, C D’Alessandro, C Gatt, S O'Connor, J Mansheim, K McKenzie and G Siciliano for expert animal care; B Helbert for genotyping; J Corbin and J McManus for automated blood analysis. We thank L O Reilly for helping with the TUNEL assays. We thank KA Sarosiek for the helpful discussion of some results. This work was supported by grants and fellowships from the Deutsche Krebshilfe (Dr Mildred Scheel post-doctoral fellowship to KB), Cancer Council of Victoria (SG, AD 'Sydney Parker Smith Postdoctoral Fellowship'), Leukaemia Foundation Australia (SG), the Lady Tata Memorial Trust (SG), Cure Brain Cancer Australia (AS), the National Health and Medical Research Council (Program Grants \#1016701 and 1016647, NHMRC Australia Fellowship 1020363; all to AS), (Project Grants 1145728 to MJH, 1143105 to MJH and AS, and Fellowships 1156095 to $\mathrm{MJH}$ ) the Leukemia and Lymphoma Society (SCOR Grant \#7001-03 to AS), Melbourne International Research and the Melbourne International Fee Remission Scholarship 
(University of Melbourne, SG) and Cancer Therapeutics CRC Top-up Scholarship (SG, AD). The estate of Anthony (Toni) Redstone OAM, University of Melbourne International Research and International Fee Remission Scholarships (SG), Australian Postgraduate Award (ARDD, JPB), and the operational infrastructure grants through the Australian Government IRIISS and the Victorian State Government OIS.

\section{Disclosure of Conflict of Interest}

The authors declare no conflict of interest.

\section{References}

Adams, J.M., and S. Cory. 2007. The Bcl-2 apoptotic switch in cancer development and therapy. Oncogene 26:1324-1337.

Adams, J.M., and S. Cory. 2018. The BCL-2 arbiters of apoptosis and their growing role as cancer targets. Cell death and differentiation 25:27-36.

Arbour, N., J.L. Vanderluit, J.N. Le Grand, A. Jahani-Asl, V.A. Ruzhynsky, E.C. Cheung, M.A. Kelly, A.E. MacKenzie, D.S. Park, J.T. Opferman, and R.S. Slack. 2008. Mcl-1 is a key regulator of apoptosis during CNS development and after DNA damage. The Journal of neuroscience : the official journal of the Society for Neuroscience 28:6068-6078.

Beroukhim, R., C.H. Mermel, D. Porter, G. Wei, S. Raychaudhuri, J. Donovan, J. Barretina, J.S. Boehm, J. Dobson, M. Urashima, K.T. Mc Henry, R.M. Pinchback, A.H. Ligon, Y.J. Cho, L. Haery, H. Greulich, M. Reich, W. Winckler, M.S. Lawrence, B.A. Weir, K.E. Tanaka, D.Y. Chiang, A.J. Bass, A. Loo, C. Hoffman, J. Prensner, T. Liefeld, Q. Gao, D. Yecies, S. Signoretti, E. Maher, F.J. Kaye, H. Sasaki, J.E. Tepper, J.A. Fletcher, J. Tabernero, J. Baselga, M.S. Tsao, F. Demichelis, M.A. Rubin, P.A. Janne, M.J. Daly, C. Nucera, R.L. Levine, B.L. Ebert, S. Gabriel, A.K. Rustgi, C.R. Antonescu, M. Ladanyi, A. Letai, L.A. Garraway, M. Loda, D.G. Beer, L.D. True, A. Okamoto, S.L. Pomeroy, S. Singer, T.R. Golub, E.S. Lander, G. Getz, W.R. Sellers, and M. Meyerson. 2010. The landscape of somatic copy-number alteration across human cancers. Nature 463:899-905.

Bouillet, P., S. Cory, L.C. Zhang, A. Strasser, and J.M. Adams. 2001. Degenerative disorders caused by $\mathrm{Bcl}-2$ deficiency prevented by loss of its BH3-only antagonist Bim. Developmental cell 1:645-653.

Bouillet, P., D. Metcalf, D.C. Huang, D.M. Tarlinton, T.W. Kay, F. Kontgen, J.M. Adams, and A. Strasser. 1999a. Proapoptotic Bcl-2 relative Bim required for certain apoptotic responses, leukocyte homeostasis, and to preclude autoimmunity. Science 286:1735-1738. 
Bouillet, P., D. Metcalf, D.C.S. Huang, D.M. Tarlinton, T.W.H. Kay, F. Köntgen, J.M. Adams, and A. Strasser. 1999b. Proapoptotic Bcl-2 relative Bim required for certain apoptotic responses, leukocyte homeostasis, and to preclude autoimmunity. Science 286:1735-1738.

Brennan, M.S., C. Chang, L. Tai, G. Lessene, A. Strasser, G. Dewson, G.L. Kelly, and M.J. Herold. 2018. Humanized Mcl-1 mice enable accurate preclinical evaluation of MCL-1 inhibitors destined for clinical use. Blood 132:1573-1583.

Brinkmann, K., S. Grabow, C.D. Hyland, C.E. Teh, W.S. Alexander, M.J. Herold, and A. Strasser. 2017. The combination of reduced MCL-1 and standard chemotherapeutics is tolerable in mice. Cell death and differentiation 24:2032-2043.

Caenepeel, S., S.P. Brown, B. Belmontes, G. Moody, K.S. Keegan, D. Chui, D.A. Whittington, X. Huang, L. Poppe, A.C. Cheng, M. Cardozo, J. Houze, Y. Li, B. Lucas, N.A. Paras, X. Wang, J.P. Taygerly, M. Vimolratana, M. Zancanella, L. Zhu, E. Cajulis, T. Osgood, J. Sun, L. Damon, R.K. Egan, P. Greninger, J.D. McClanaghan, J. Gong, D. Moujalled, G. Pomilio, P. Beltran, C.H. Benes, A.W. Roberts, D.C. Huang, A. Wei, J. Canon, A. Coxon, and P.E. Hughes. 2018. AMG 176, a Selective MCL1 Inhibitor, Is Effective in Hematologic Cancer Models Alone and in Combination with Established Therapies. Cancer Discov 8:1582-1597.

Campbell, K.J., and S.W.G. Tait. 2018. Targeting BCL-2 regulated apoptosis in cancer. Open Biol 8:

Cohen, E.P. 2000. Radiation nephropathy after bone marrow transplantation. Kidney international 58:903-918.

Cohen, E.P., P. Pais, and J.E. Moulder. 2010. Chronic kidney disease after hematopoietic stem cell transplantation. Seminars in nephrology 30:627-634.

Cohen, E.P., and M.E. Robbins. 2003. Radiation nephropathy. Seminars in nephrology 23:486-499.

Cragg, M.S., E.S. Jansen, M. Cook, C. Harris, A. Strasser, and C.L. Scott. 2008. Treatment of B-RAF mutant human tumor cells with a MEK inhibitor requires Bim and is enhanced by a $\mathrm{BH} 3$ mimetic. J Clin Invest 118:3651-3659.

Cragg, M.S., J. Kuroda, H. Puthalakath, D.C. Huang, and A. Strasser. 2007. Gefitinib-induced killing of NSCLC cell lines expressing mutant EGFR requires BIM and can be enhanced by BH3 mimetics. PLoS Med 4:1681-1689; discussion 1690.

Davis, S.L., and T.J. Littlewood. 2012. The investigation and treatment of secondary anaemia. Blood Rev 26:65-71.

Del Gaizo Moore, V., and A. Letai. 2013. BH3 profiling--measuring integrated function of the mitochondrial apoptotic pathway to predict cell fate decisions. Cancer letters 332:202205.

Dracham, C.B., A. Shankar, and R. Madan. 2018. Radiation induced secondary malignancies: a review article. Radiat Oncol J 36:85-94.

Erlacher, M., E.M. Michalak, P.N. Kelly, V. Labi, H. Niederegger, L. Coultas, J.M. Adams, A. Strasser, and A. Villunger. 2005. BH3-only proteins Puma and Bim are rate-limiting for gammaradiation- and glucocorticoid-induced apoptosis of lymphoid cells in vivo. Blood 106:41314138.

Francois, A., F. Milliat, O. Guipaud, and M. Benderitter. 2013. Inflammation and immunity in radiation damage to the gut mucosa. Biomed Res Int 2013:123241.

Gavrieli, Y., Y. Sherman, and S.A. Ben-Sasson. 1992. Identification of programmed cell death in situ via specific labeling of nuclear DNA fragmentation. J Cell Biol 119:493-501. 
Glaser, S.P., E.F. Lee, E. Trounson, P. Bouillet, A. Wei, W.D. Fairlie, D.J. Izon, J. Zuber, A.R. Rappaport, M.J. Herold, W.S. Alexander, S.W. Lowe, L. Robb, and A. Strasser. 2012. Antiapoptotic Mcl-1 is essential for the development and sustained growth of acute myeloid leukemia. Genes \& development 26:120-125.

Gorczyca, W., S. Bruno, R. Darzynkiewicz, J. Gong, and Z. Darzynkiewicz. 1992. DNA strand breaks occurring during apoptosis - their early insitu detection by the terminal deoxynucleotidyl transferase and nick translation assays and prevention by serine protease inhibitors. Int J Oncol 1:639-648.

Hanahan, D., and R.A. Weinberg. 2000. The hallmarks of cancer. Cell 100:57-70.

Hanahan, D., and R.A. Weinberg. 2011. Hallmarks of cancer: the next generation. Cell 144:646674.

Kelly, G.L., S. Grabow, S.P. Glaser, L. Fitzsimmons, B.J. Aubrey, T. Okamoto, L.J. Valente, M. Robati, L. Tai, W.D. Fairlie, E.F. Lee, M.S. Lindstrom, K.G. Wiman, D.C. Huang, P. Bouillet, M. Rowe, A.B. Rickinson, M.J. Herold, and A. Strasser. 2014. Targeting of MCL-1 kills MYC-driven mouse and human lymphomas even when they bear mutations in p53. Genes \& development 28:58-70.

Khan, S., X. Zhang, D. Lv, Q. Zhang, Y. He, P. Zhang, X. Liu, D. Thummuri, Y. Yuan, J.S. Wiegand, J. Pei, W. Zhang, A. Sharma, C.R. McCurdy, V.M. Kuruvilla, N. Baran, A.A. Ferrando, Y.M. Kim, A. Rogojina, P.J. Houghton, G. Huang, R. Hromas, M. Konopleva, G. Zheng, and D. Zhou. 2019. A selective BCL-XL PROTAC degrader achieves safe and potent antitumor activity. Nature medicine 25:1938-1947.

Kim, J., and Y. Jung. 2017. Radiation-induced liver disease: current understanding and future perspectives. Exp Mol Med 49:e359.

Kotschy, A., Z. Szlavik, J. Murray, J. Davidson, A.L. Maragno, G. Le Toumelin-Braizat, M. Chanrion, G.L. Kelly, J.N. Gong, D.M. Moujalled, A. Bruno, M. Csekei, A. Paczal, Z.B. Szabo, S. Sipos, G. Radics, A. Proszenyak, B. Balint, L. Ondi, G. Blasko, A. Robertson, A. Surgenor, P. Dokurno, I. Chen, N. Matassova, J. Smith, C. Pedder, C. Graham, A. Studeny, G. LysiakAuvity, A.M. Girard, F. Grave, D. Segal, C.D. Riffkin, G. Pomilio, L.C. Galbraith, B.J. Aubrey, M.S. Brennan, M.J. Herold, C. Chang, G. Guasconi, N. Cauquil, F. Melchiore, N. GuigalStephan, B. Lockhart, F. Colland, J.A. Hickman, A.W. Roberts, D.C. Huang, A.H. Wei, A. Strasser, G. Lessene, and O. Geneste. 2016. The MCL1 inhibitor S63845 is tolerable and effective in diverse cancer models. Nature 538:477-482.

Lessene, G., P.E. Czabotar, B.E. Sleebs, K. Zobel, K.N. Lowes, J.M. Adams, J.B. Baell, P.M. Colman, K. Deshayes, W.J. Fairbrother, J.A. Flygare, P. Gibbons, W.J. Kersten, S. Kulasegaram, R.M. Moss, J.P. Parisot, B.J. Smith, I.P. Street, H. Yang, D.C. Huang, and K.G. Watson. 2013. Structure-guided design of a selective $\mathrm{BCL}-\mathrm{X}(\mathrm{L})$ inhibitor. Nature chemical biology 9:390397.

Leverson, J.D., D.C. Phillips, M.J. Mitten, E.R. Boghaert, D. Diaz, S.K. Tahir, L.D. Belmont, P. Nimmer, Y. Xiao, X.M. Ma, K.N. Lowes, P. Kovar, J. Chen, S. Jin, M. Smith, J. Xue, H. Zhang, A. Oleksijew, T.J. Magoc, K.S. Vaidya, D.H. Albert, J.M. Tarrant, N. La, L. Wang, Z.F. Tao, M.D. Wendt, D. Sampath, S.H. Rosenberg, C. Tse, D.C. Huang, W.J. Fairbrother, S.W. Elmore, and A.J. Souers. 2015. Exploiting selective BCL-2 family inhibitors to dissect cell survival dependencies and define improved strategies for cancer therapy. Sci Transl Med 7:279ra240. 
Marks, L.B., X. Yu, Z. Vujaskovic, W. Small, Jr., R. Folz, and M.S. Anscher. 2003. Radiation-induced lung injury. Semin Radiat Oncol 13:333-345.

Mason, K.D., M.R. Carpinelli, J.I. Fletcher, J.E. Collinge, A.A. Hilton, S. Ellis, P.N. Kelly, P.G. Ekert, D. Metcalf, A.W. Roberts, D.C. Huang, and B.T. Kile. 2007. Programmed anuclear cell death delimits platelet life span. Cell 128:1173-1186.

Mehta, V. 2005. Radiation pneumonitis and pulmonary fibrosis in non-small-cell lung cancer: pulmonary function, prediction, and prevention. International journal of radiation oncology, biology, physics 63:5-24.

Merino, D., G.L. Kelly, G. Lessene, A.H. Wei, A.W. Roberts, and A. Strasser. 2018. BH3-Mimetic Drugs: Blazing the Trail for New Cancer Medicines. Cancer cell 34:879-891.

Motoyama, N., F. Wang, K.A. Roth, H. Sawa, K. Nakayama, K. Nakayama, I. Negishi, S. Senju, Q. Zhang, S. Fujii, and et al. 1995. Massive cell death of immature hematopoietic cells and neurons in Bcl-x-deficient mice. Science 267:1506-1510.

Ogilvy-Stuart, A.L., and S.M. Shalet. 1993. Effect of radiation on the human reproductive system. Environ Health Perspect 101 Suppl 2:109-116.

Olcina, M.M., and A.J. Giaccia. 2016. Reducing radiation-induced gastrointestinal toxicity - the role of the PHD/HIF axis. J Clin Invest 126:3708-3715.

Oltersdorf, T., S.W. Elmore, A.R. Shoemaker, R.C. Armstrong, D.J. Augeri, B.A. Belli, M. Bruncko, T.L. Deckwerth, J. Dinges, P.J. Hajduk, M.K. Joseph, S. Kitada, S.J. Korsmeyer, A.R. Kunzer, A. Letai, C. Li, M.J. Mitten, D.G. Nettesheim, S. Ng, P.M. Nimmer, J.M. O'Connor, A. Oleksijew, A.M. Petros, J.C. Reed, W. Shen, S.K. Tahir, C.B. Thompson, K.J. Tomaselli, B. Wang, M.D. Wendt, H. Zhang, S.W. Fesik, and S.H. Rosenberg. 2005. An inhibitor of Bcl-2 family proteins induces regression of solid tumours. Nature 435:677-681.

Opferman, J.T., H. Iwasaki, C.C. Ong, H. Suh, S. Mizuno, K. Akashi, and S.J. Korsmeyer. 2005. Obligate role of anti-apoptotic MCL-1 in the survival of hematopoietic stem cells. Science 307:1101-1104.

Print, C.G., K.L. Loveland, L. Gibson, T. Meehan, A. Stylianou, N. Wreford, D. de Kretser, D. Metcalf, F. Kontgen, J.M. Adams, and S. Cory. 1998. Apoptosis regulator bcl-w is essential for spermatogenesis but appears otherwise redundant. Proceedings of the National Academy of Sciences of the United States of America 95:12424-12431.

Riedl, S.J., and G.S. Salvesen. 2007. The apoptosome: signalling platform of cell death. Nature reviews. Molecular cell biology 8:405-413.

Rinkenberger, J.L., S. Horning, B. Klocke, K. Roth, and S.J. Korsmeyer. 2000. Mcl-1 deficiency results in peri-implantation embryonic lethality. Genes \& development 14:23-27.

Rucker, E.B., 3rd, P. Dierisseau, K.U. Wagner, L. Garrett, A. Wynshaw-Boris, J.A. Flaws, and L. Hennighausen. 2000. Bcl-x and Bax regulate mouse primordial germ cell survival and apoptosis during embryogenesis. Molecular endocrinology 14:1038-1052.

Salvamoser, R., K. Brinkmann, L.A. O'Reilly, L. Whitehead, A. Strasser, and M.J. Herold. 2019. Characterisation of mice lacking the inflammatory caspases-1/11/12 reveals no contribution of caspase-12 to cell death and sepsis. Cell death and differentiation 26:1124-1137.

Schaefer, B.C., M.L. Schaefer, J.W. Kappler, P. Marrack, and R.M. Kedl. 2001. Observation of antigen-dependent CD8+ T-cell/ dendritic cell interactions in vivo. Cell Immunol 214:110122. 
Schenk, R.L., S. Tuzlak, E.M. Carrington, Y. Zhan, S. Heinzel, C.E. Teh, D.H. Gray, L. Tai, A.M. Lew, A. Villunger, A. Strasser, and M.J. Herold. 2017. Characterisation of mice lacking all functional isoforms of the pro-survival BCL-2 family member A1 reveals minor defects in the haematopoietic compartment. Cell death and differentiation 24:534-545.

Seibler, J., B. Zevnik, B. Kuter-Luks, S. Andreas, H. Kern, T. Hennek, A. Rode, C. Heimann, N. Faust, G. Kauselmann, M. Schoor, R. Jaenisch, K. Rajewsky, R. Kuhn, and F. Schwenk. 2003. Rapid generation of inducible mouse mutants. Nucleic Acids Res 31:e12.

Souers, A.J., J.D. Leverson, E.R. Boghaert, S.L. Ackler, N.D. Catron, J. Chen, B.D. Dayton, H. Ding, S.H. Enschede, W.J. Fairbrother, D.C. Huang, S.G. Hymowitz, S. Jin, S.L. Khaw, P.J. Kovar, L.T. Lam, J. Lee, H.L. Maecker, K.C. Marsh, K.D. Mason, M.J. Mitten, P.M. Nimmer, A. Oleksijew, C.H. Park, C.M. Park, D.C. Phillips, A.W. Roberts, D. Sampath, J.F. Seymour, M.L. Smith, G.M. Sullivan, S.K. Tahir, C. Tse, M.D. Wendt, Y. Xiao, J.C. Xue, H. Zhang, R.A. Humerickhouse, S.H. Rosenberg, and S.W. Elmore. 2013. ABT-199, a potent and selective $\mathrm{BCL}-2$ inhibitor, achieves antitumor activity while sparing platelets. Nature medicine 19:202-208.

Tait, S.W., and D.R. Green. 2010. Mitochondria and cell death: outer membrane permeabilization and beyond. Nature reviews. Molecular cell biology 11:621-632.

Thomas, R.L., D.J. Roberts, D.A. Kubli, Y. Lee, M.N. Quinsay, J.B. Owens, K.M. Fischer, M.A. Sussman, S. Miyamoto, and A.B. Gustafsson. 2013. Loss of MCL-1 leads to impaired autophagy and rapid development of heart failure. Genes \& development 27:1365-1377.

Tse, C., A.R. Shoemaker, J. Adickes, M.G. Anderson, J. Chen, S. Jin, E.F. Johnson, K.C. Marsh, M.J. Mitten, P. Nimmer, L. Roberts, S.K. Tahir, Y. Xiao, X. Yang, H. Zhang, S. Fesik, S.H. Rosenberg, and S.W. Elmore. 2008. ABT-263: a potent and orally bioavailable Bcl-2 family inhibitor. Cancer research 68:3421-3428.

Tuzlak, S., R.L. Schenk, A. Vasanthakumar, S.P. Preston, M.D. Haschka, D. Zotos, A. Kallies, A. Strasser, A. Villunger, and M.J. Herold. 2017. The BCL-2 pro-survival protein A1 is dispensable for $T$ cell homeostasis on viral infection. Cell death and differentiation 24:523533.

Uhlen, M., E. Bjorling, C. Agaton, C.A. Szigyarto, B. Amini, E. Andersen, A.C. Andersson, P. Angelidou, A. Asplund, C. Asplund, L. Berglund, K. Bergstrom, H. Brumer, D. Cerjan, M. Ekstrom, A. Elobeid, C. Eriksson, L. Fagerberg, R. Falk, J. Fall, M. Forsberg, M.G. Bjorklund, K. Gumbel, A. Halimi, I. Hallin, C. Hamsten, M. Hansson, M. Hedhammar, G. Hercules, C. Kampf, K. Larsson, M. Lindskog, W. Lodewyckx, J. Lund, J. Lundeberg, K. Magnusson, E. Malm, P. Nilsson, J. Odling, P. Oksvold, I. Olsson, E. Oster, J. Ottosson, L. Paavilainen, A. Persson, R. Rimini, J. Rockberg, M. Runeson, A. Sivertsson, A. Skollermo, J. Steen, M. Stenvall, F. Sterky, S. Stromberg, M. Sundberg, H. Tegel, S. Tourle, E. Wahlund, A. Walden, J. Wan, H. Wernerus, J. Westberg, K. Wester, U. Wrethagen, L.L. Xu, S. Hober, and F. Ponten. 2005. A human protein atlas for normal and cancer tissues based on antibody proteomics. Molecular \& cellular proteomics : MCP 4:1920-1932.

Uhlen, M., C. Zhang, S. Lee, E. Sjostedt, L. Fagerberg, G. Bidkhori, R. Benfeitas, M. Arif, Z. Liu, F. Edfors, K. Sanli, K. von Feilitzen, P. Oksvold, E. Lundberg, S. Hober, P. Nilsson, J. Mattsson, J.M. Schwenk, H. Brunnstrom, B. Glimelius, T. Sjoblom, P.H. Edqvist, D. Djureinovic, P. Micke, C. Lindskog, A. Mardinoglu, and F. Ponten. 2017. A pathology atlas of the human cancer transcriptome. Science 357: 
Veis, D.J., C.M. Sorenson, J.R. Shutter, and S.J. Korsmeyer. 1993. Bcl-2-deficient mice demonstrate fulminant lymphoid apoptosis, polycystic kidneys, and hypopigmented hair. Cell 75:229-240.

Villunger, A., E.M. Michalak, L. Coultas, F. Mullauer, G. Bock, M.J. Ausserlechner, J.M. Adams, and A. Strasser. 2003. p53- and drug-induced apoptotic responses mediated by BH3-only proteins puma and noxa. Science 302:1036-1038.

Vooijs, M., J. Jonkers, and A. Berns. 2001. A highly efficient ligand-regulated Cre recombinase mouse line shows that LoxP recombination is position dependent. EMBO Rep 2:292-297.

Wagner, K.U., E. Claudio, E.B. Rucker, 3rd, G. Riedlinger, C. Broussard, P.L. Schwartzberg, U. Siebenlist, and L. Hennighausen. 2000. Conditional deletion of the Bcl-x gene from erythroid cells results in hemolytic anemia and profound splenomegaly. Development 127:4949-4958.

Wang, X., M. Bathina, J. Lynch, B. Koss, C. Calabrese, S. Frase, J.D. Schuetz, J.E. Rehg, and J.T. Opferman. 2013. Deletion of MCL-1 causes lethal cardiac failure and mitochondrial dysfunction. Genes \& development 27:1351-1364.

Weiss, G., and L.T. Goodnough. 2005. Anemia of chronic disease. N Engl J Med 352:1011-1023.

Wilson, W.H., O.A. O'Connor, M.S. Czuczman, A.S. LaCasce, J.F. Gerecitano, J.P. Leonard, A. Tulpule, K. Dunleavy, H. Xiong, Y.L. Chiu, Y. Cui, T. Busman, S.W. Elmore, S.H. Rosenberg, A.P. Krivoshik, S.H. Enschede, and R.A. Humerickhouse. 2010. Navitoclax, a targeted highaffinity inhibitor of BCL-2, in lymphoid malignancies: a phase 1 dose-escalation study of safety, pharmacokinetics, pharmacodynamics, and antitumour activity. Lancet Oncol 11:1149-1159.

\section{Abbreviations:}

AST - Aspartate aminostransferase; ALT - alanine aminostransferase; CFU-e - colony forming unit-erythroid; EPO - erythropoietin; GIS - gastro intestinal syndrome; HCT hematocrit; HGB - hemoglobin; IR - $\gamma$-irradiation; LDH - lactate dehydrogenase; MOMPmitochondrial outer membrane permeabilization; NLR - neutrophil to lymphocyte ratio; RBCs - red blood cells; RISM - radiation-induced secondary malignancies; RN Radiation-induced nephropathy; ROS - reactive oxygen species; SHG - second harmony generation; TBI - total body irradiation; WBCs - white blood cells; 5-FU - 5-Fluorouracil 


\section{Figure Legends}

Figure 1: The inducible deletion of $B C L-X L$ causes severe anemia even in chimeric mice that are $B C L-X L$ sufficient in all hematopoietic cell populations. (A) $B c l-x^{f / f f l} ; R o s a C r e E R T 2^{+/ K i}$ or, as controls, $B c l-x^{f / / f l}$ and RosaCreERT2 ${ }^{+/ K i}$ mice (age 9-12 weeks, males and females, numbers indicated) were treated with tamoxifen ( $200 \mathrm{mg} / \mathrm{kg} / \mathrm{body}$ weight administered in 3 daily doses by oral gavage) to induce CreERT2-mediated deletion of the floxed $B c l-x$ alleles. Mice were monitored for up to 200 days post-treatment with tamoxifen. (B) $B c l-x^{f l / f l} ; R o s a C r e E R T 2^{+/ K i}$ or, as controls, $\mathrm{Bcl}-\mathrm{x}^{\mathrm{fl} / \mathrm{fl}}$ and RosaCreERT2${ }^{+/ K i}$ mice (males and females, aged 8-14 weeks, numbers indicated in the figure legend) were lethally $\gamma$-irradiated ( $2 \times 5.5 \mathrm{~Gy}, 3 \mathrm{~h}$ apart) and reconstituted with bone marrow from UBC-GFP mice (referred to as GFP-Chimeras). After 8 weeks, reconstituted mice were treated with tamoxifen $(200 \mathrm{mg} / \mathrm{kg}$ body weight administered in 3 daily doses oral gavage) and monitored for up to 200 days (termination of the experiment). (A-B) Data are presented as \% survival post-treatment with tamoxifen and statistical significance was assessed using the Mantel-Cox (Log-rank) test; ${ }^{* * *} p<0.0001$. (C) Total counts of platelets, (D) red blood cells (RBC), (E) hemoglobin (HGB) content and (F) hematocrit (HCT) of tamoxifentreated mice were determined by ADVIA. (G) Spleen weights were measured in sick mice (at sacrifice) or, for the healthy control mice, at the termination of the experiment. (C-G) Data are presented as mean \pm SEM. Each data point represents an individual mouse and numbers are indicated. Statistical significance was assessed using the Student's t-test; ${ }^{* * *} p<0.0001 .(\mathbf{H})$ Representative image of enlarged spleens from two $B c /-x^{f / f f l} ; R o s a C r e E R T 2^{K / /+}$ mice and agematched control $B c /-x^{f / f f l}$ and RosaCreERT2 $2^{+/ K i}$ mice (34 days after treatment). (I) Histological analysis of H\&E-stained sections of spleens of tamoxifen-treated mice of the indicated genotypes. 
Figure 2: The combination of $\gamma$-radiation and inducible deletion of BCL-XL causes neither inflammation, hematopoietic malignancy nor liver damage. $B c /-x^{f / f f l} ; R o s a C r e E R T 2^{+/ K i}(n=8)$ or, as controls, $B c /-x^{f l / f l}(n=6)$ and RosaCreERT2 ${ }^{+/ K i}(n=12)$ mice as well as $B c /-$ $x^{f|f| f l} ;$ RosaCreERT2 $2^{+/ K i} ;$ GFP-chimeras $(\mathrm{n}=21)$, or, as controls $B c l-x^{f \mid / f l} ; G F P$-chimeras $(\mathrm{n}=6)$ and RosaCreERT2 ${ }^{+/ K i} ;$ GFP-chimeras $(\mathrm{n}=6)$ (age 8-14 weeks, males and females) were treated with tamoxifen (200 mg/kg/body weight administered in 3 daily doses by oral gavage) to induce CreERT2-mediated deletion of the floxed Bcl-x alleles. (A) Total white blood cell counts (WBC) were analyzed by ADVIA in sick mice or at the termination of the experiment (healthy control mice). Data are presented as mean \pm SEM. Each data point represents an individual mouse and $\mathrm{n}$ numbers are indicated. No statistically significant differences were observed. (B) The neutrophil/lymphocyte ratio $(\mathrm{NLR})$ is presented as mean \pm SEM for sick $B c /$ $x^{f / / f l} ;$ RosaCreERT2 $2^{+/ K i} ;$ GFP-chimeras $(\mathrm{n}=21)$ or healthy control RosaCreERT2 ${ }^{+/ K i} ;$ GFP-chimeras $(n=6)$ at the termination of the experiment. Data are presented as mean \pm SEM. Each data point represents an individual mouse. Statistical significance was assessed using the Student's t-test; ${ }^{*} p<0.05$. (C) Histological analysis of H\&E-stained sections of the sternum of sick $B C l-$ $x^{f / f f l} ;$ RosaCreERT2 ${ }^{+/ K i} ;$ GFP-chimeras or healthy wild-type and RosaCreERT2 ${ }^{+/ K i} ;$ GFP-chimera control mice at the indicated time points post-treatment with tamoxifen. (dpt=days post treatment). (D) Histological analysis of H\&E-stained sections of the livers of sick mice or age-matched healthy control wild-type mice or healthy RosaCreERT2 ${ }^{+/ K i} ; G F P$-chimeras at the termination of the experiment (dpt=days post-treatment). (E) ALT (panel), AST (left middle panel) and bilirubin levels (right panel) in the serum were determined in sick $B c l-x^{f / / f l} ;$ RosaCreERT2 ${ }^{+/ K i} ; G F P$-chimeras $(\mathrm{n}=18)$ or in healthy RosaCreERT2 ${ }^{+/ K i} ;$ GFP-chimeras $(\mathrm{n}=4)$ at the termination of the experiment. Data are presented as mean \pm SEM. Each data point represents one individual mouse. Statistical significance was assessed using Student's t-test; ${ }^{* *} \mathrm{p}<0.01 . \mathrm{nd}=$ not detected. 
Figure 3: The combination of $\gamma$-radiation and inducible deletion of BCL-XL causes severe kidney damage. $B c /-x^{f f / f l} ; R o s a C r e E R T 2^{+/ K i}(n=7)$ or, as controls, $B c l-x^{f / / f l}(n=8)$ and RosaCreERT2 $^{+/ K i}(\mathrm{n}=16)$ mice as well as $B c /-x^{f / f f l} ;$ RosaCreERT2 ${ }^{+/ K i} ; G F P$-chimeras $(\mathrm{n}=5), B c l-$ $x^{f / f f l} ; G F P$-chimeras $(\mathrm{n}=8)$ and RosaCreERT2 ${ }^{+/ K i} ;$ GFP-chimeras $(\mathrm{n}=6)($ age 8 -14 weeks, males and females) were treated with tamoxifen $(200 \mathrm{mg} / \mathrm{kg} / \mathrm{body}$ weight administered in 3 daily doses by oral gavage) to induce CreERT2-mediated deletion of the floxed $B c l-x$ alleles. (A) Kidney weights were measured in sick $B \mathrm{Cl}-\mathrm{x}^{\mathrm{fl} / \mathrm{fl} ;} ;$ RosaCreERT2 $2^{+/ K i} ;$ GFP-chimeras (at sacrifice) or, for the healthy control mice, at the termination of the experiment. Data are presented as mean \pm SEM. Each data point represents one individual mouse. Statistical significance was assessed using Student's ttest; ${ }^{*} p<0.05,{ }^{* * *} p<0.001$. (B) Picture showing both kidneys from age-matched healthy control wild-type mice (left) and sick $B c /-x^{f / / f l} ; R o s a C r e E R T 2^{+/ K i} ; G F P$-chimeras (right). (C) Histological analysis of H\&E-stained sections of the kidneys of age-matched healthy control mice or sick $\mathrm{Bcl}$ $x^{f l / f l} ;$ RosaCreERT2 $2^{+/ K i} ;$ GFP-chimeras as indicated, showing from left to right, shrunken scarred kidney, segmental chronic tubulo-interstitial disease, accumulation of cellular debris and amorphous material within the collecting ducts of the papilla. The higher magnification shows tubular epithelial degeneration, apoptosis and segmental secondary glomerular sclerosis. Pictures are representative of at least 5 mice for each genotype. (D) Multiphoton analysis of fixed sections of the kidney of age-matched healthy RosaCreERT2 ${ }^{+/ K i} ;$ GFP-chimeras (left) or sick Bcl$x^{f / f f l} ;$ RosaCreERT2 $2^{+/ K i} ;$ GFP-chimeras (right). Pictures are representative of at least 3 mice for each genotype. green=second harmony, blue=short wavelength autofluorescence.

Figure 4: The combination of $\gamma$-radiation and inducible deletion of BCL-XL causes apoptosis of proximal renal tubule epithelial cells. (A) TUNEL staining of kidney sections from control RosaCreERT2 ${ }^{+/ K i}$, Bcl-x ${ }^{f / / f l} ;$ RosaCreERT2 ${ }^{+/ K i}$, RosaCreERT2 ${ }^{+/ K i} ; G F P$-chimeras or $B c l-$ $x^{f / f f l} ;$ RosaCreERT2 $2^{+/ K i} ;$ GFP-chimeras at the indicated time points post-tamoxifen treatment (200 
$\mathrm{mg} / \mathrm{kg} / \mathrm{body}$ weight administered in 3 daily doses by oral gavage) or $\gamma$-irradiation ( $2 \times 550 \mathrm{Rad}$ ), as indicated. Slides were counterstained with hematoxylin. Arrow heads indicate examples of TUNEL positive (apoptotic) cells. (B) TUNEL positive cells were quantified using a personalized script for the Imaga J software. Kidney sections were divided into $\sim 40$ microscopic images and the total numbers of blue and brown (TUNEL positive) nuclei were determined. The percentages of TUNEL positive nuclei were calculated for each picture. The average value for each kidney section was then determined and plotted as a single data point. Error bars represent SEM from at least 3 independent samples for each genotype. Statistical significance was assessed using one-way ANOVA analysis with Tukey's multiple comparisons test (comparing control RosaCreERT2 $2^{+/ K i}$ with $B c /-x^{f / / f l} ; R o s a C r e E R T 2^{+/ K i}$ and control RosaCreERT2 $2^{+/ K i} ;$ GFP-chimeras with $B c l-x^{f l / f l} ;$ RosaCreERT2 ${ }^{+/ K i} ;$ GFP-chimeras. ${ }^{* * *} p<0.001$

Figure 5: Concomitant loss of BIM or PUMA delays the fatal kidney disease caused by the combination of $\gamma$-irradiation and inducible deletion of BCL-XL. Mice of the indicated genotypes (males and females mixed, aged 10-14 weeks, numbers are indicated) were lethally irradiated ( 2 x 5.5 Gy, $3 \mathrm{~h}$ apart) and reconstituted with bone marrow from UBC-GFP mice. After 8 weeks, reconstituted mice were treated with tamoxifen $(200 \mathrm{mg} / \mathrm{kg}$ body weight administered in 3 daily doses by oral gavage) and monitored for at least 240 days. (A, B) Data are presented as $\%$ survival and statistical significance was assessed using the Mantel-Cox (Log-rank) test. ${ }^{*} \mathrm{p}<0.05,{ }^{* * * *} \mathrm{p}<0.0001$. The survival curves for the $B c l-x^{f / / f l} ;$ RosaCreERT2 ${ }^{+/ K i} ;$ GFP-chimeras are the same as those shown in Figure $1 \mathrm{~B}$ and presented here for ease of comparison. (C) Histological analysis of H\&E-stained sections of the kidneys of sick mice of the indicated genotypes at the indicated time points ( $\mathrm{dpt}=$ days post-tamoxifen treatment). Pictures are representative of at least 3 mice for each genotype. (D) Total red blood cell (RBC) count, (E) hematocrit $(\mathrm{HCT})$ and $(\mathrm{F})$ hemoglobin $(\mathrm{HGB})$ content were determined by ADVIA in the blood of 
sick mice of the indicated genotypes or at the termination of the experiment for healthy controls.

(D-F) Data are presented as mean \pm SEM. Each data point represents one individual mouse. Numbers of miceare indicated. Statistical significance was assessed using Student's t-test; ${ }^{* * *} p<0.001 ; \quad{ }^{* * * *} p<0.0001$. Data for the Bcl- $x^{f / / f l} ;$ RosaCreERT2 ${ }^{+/ K i} ;$ GFP-chimeras and RosaCreERT2 ${ }^{+/ K i} ;$ GFP-chimeras are the same as those shown in Figure $1 \mathrm{D}-\mathrm{F}$ and are shown here for ease of comparison.

Figure 6: Pharmacological inhibition of BCL-XL in combination with DNA damage-inducing chemotherapeutics or $\gamma$-radiation at clinically relevant doses is tolerated in mice. (A) GFPChimeras were treated with the BCL-XL inhibitor A1331852 ( $n=8,5$ doses by oral gavage, 25 $\mathrm{mg} / \mathrm{kg}$ body weight each dose). Control groups ( $\mathrm{n}=8$ each group) include untreated GFPChimeras and un-irradiated C57BL/6-Ly5.1 (wild-type) mice treated with A1331852 or left untreated. Mice were monitored for up to 200 days post-treatment (dpt). Data are presented as \% survival. (B) C57BL/6-Ly5.1 (wild-type) mice (females, aged 10 weeks) were treated with Cyclophosphamide ( $\mathrm{n}=7,150 \mathrm{mg} / \mathrm{kg}$ body weight, 1 dose i.v.) or 5-Fluorouracil (5-FU, $\mathrm{n}=7,100$ $\mathrm{mg} / \mathrm{kg}$ body weight, 1 dose i.v.) and after 5 days additionally treated with A1331852 (5 doses by oral gavage, $100 \mathrm{mg} / \mathrm{kg}$ body weight each dose). Control groups ( $\mathrm{n}=7$ each group) include C57BL/6-Ly5.1 (wild-type) mice (females, aged 10 weeks) treated with A1331852 alone, Cyclophosphamide alone, 5-FU alone or left untreated. Mice were monitored for up to 150 days post-treatment (dpt). Data are presented as \% survival. (C) C57BL/6-Ly5.1 (wild-type) mice (females, aged 10 weeks) were treated with $\mathrm{A} 1331852(n=7,5$ doses by oral gavage, 25 or 100 $\mathrm{mg} / \mathrm{kg}$ body weight each dose). Total platelet counts were determined by ADVIA at the indicated time points. (D-E) Total red blood cell count (RBC), platelet count, hemoglobin (HGB) content and hematocrit (HCT) were determined by ADVIA as indicated in the blood of (D) drug-treated GFPChimeras or control mice ( $n=8$ each group) at the termination of the experiment and $(E)$ in drug- 
treated C57BL/6-Ly5.1 (wild-type) mice or control mice at the indicated time points ( $\mathrm{n}=7$ each group). (C-E) Data are presented as mean \pm SEM. Each data point represents one individual mouse. Statistical significance was assessed using one-way ANOVA analysis with Tukey's multiple comparisons test (comparing untreated and drug-treated mice within each group). ${ }^{*} p<0.05,{ }^{* *} p<0.01,{ }^{* * *} p<0.001,{ }^{* * *} p>0.0001$.

Figure 7: Pharmacological inhibition of BCL-XL in combination with DNA damage-inducing chemotherapeutics or $\gamma$-radiation at clinically relevant doses does not impair kidney function and architecture

(A) GFP-Chimeras were treated with the BCL-XL inhibitor A1331852 ( $\mathrm{n}=8,5$ doses by oral gavage, $25 \mathrm{mg} / \mathrm{kg}$ body weight each dose). Control groups ( $\mathrm{n}=8$ each group) include untreated GFP-Chimera and un-irradiated C57BL/6-Ly5.1 (wild-type) mice treated with A1331852 or left untreated. Kidney (left panel) and spleen weights (right panel) were measured in drug-treated GFP-Chimeras or control mice at the termination of the experiment ( $n=8$ each group). (B) C57BL/6-Ly5.1 (wild-type) mice (females, aged 10 weeks) were treated with Cyclophosphamide ( $\mathrm{n}=7,150 \mathrm{mg} / \mathrm{kg}$ body weight, 1 dose $i . v$.) or 5-Fluorouracil (5-FU, n=7, $100 \mathrm{mg} / \mathrm{kg}$ body weight, 1 dose i.v.) and after 5 days additionally treated with A1331852 (5 doses by oral gavage, 100 $\mathrm{mg} / \mathrm{kg}$ body weight each dose). Control groups ( $\mathrm{n=7}$ each group) include C57BL/6-Ly5.1 (wildtype) mice (females, aged 10 weeks) treated with A1331852 alone, Cyclophosphamide alone, 5FU alone or left untreated. Kidney (left panel) and spleen weights (right panel) were measured in drug-treated mice or control mice at the termination of the experiment ( $n=7$ each group). (B) Histological analysis of H\&E-stained sections of the kidneys of drug-treated GFP-Chimeras or control mice at the termination of the experiment. Pictures are representative of at least 3 mice for each treatment group. (C) Histological analysis of H\&E-stained sections of the kidneys of 
bioRxiv preprint doi: https://doi.org/10.1101/2020.04.28.055665; this version posted April 29, 2020. The copyright holder for this preprint (which was not certified by peer review) is the author/funder. All rights reserved. No reuse allowed without permission.

drug-treated mice or control untreated mice at the termination of the experiment. Pictures are representative of at least 3 mice for each treatment group. 
Figure 1: The inducible deletion of $B C L-X L$ causes severe anemia even in chimeric mice that are BCL-XL-sufficient in all hematopoietic cell populations

bioRxiv preprint doi: https://doi.org/10.1101/2020.04.28.055665; this version posted April 29, 2020. The copyright holder for this preprint (which was not certified by peer review) is the author/funder. All rights reserved. No reuse allowed without permission.

A

B
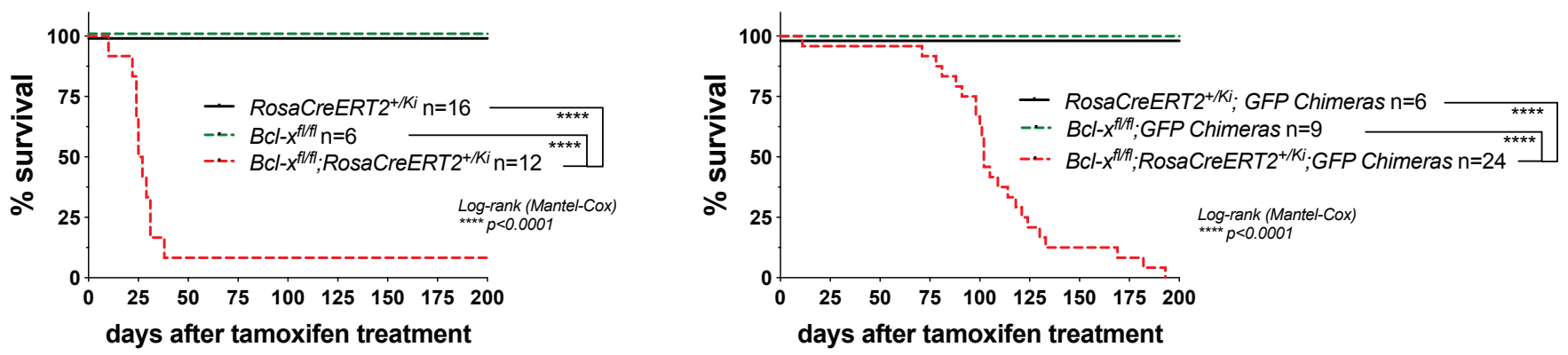

C

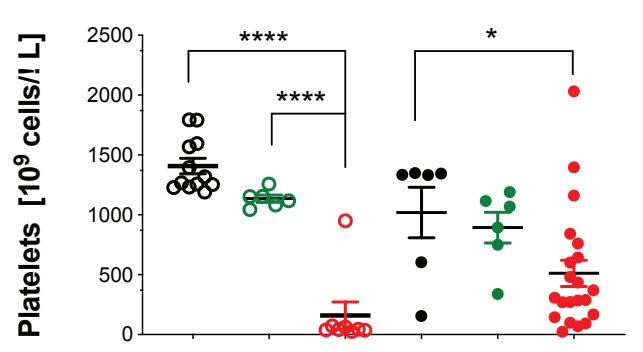

$\mathbf{E}$

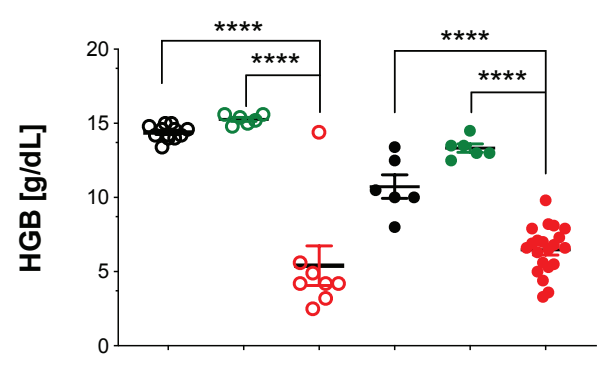

D

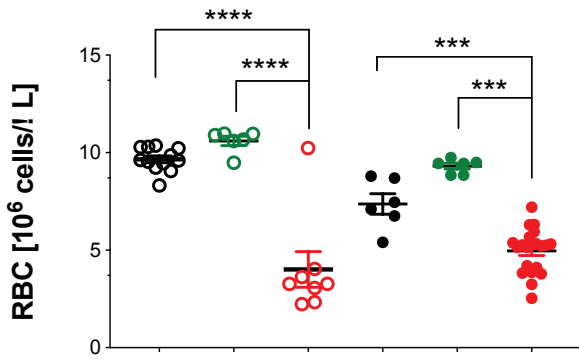

G

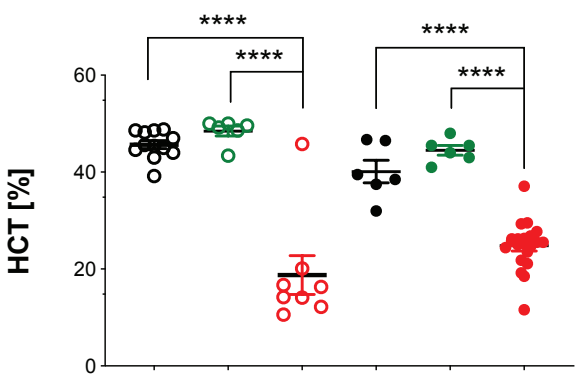

RosaCreERT2 ${ }^{+/ K i} \mathrm{n}=12$

O $B c l-x^{f / f t} \mathrm{n}=6$

O Bcl-x $x^{f / f t} ;$ RosaCreERT2 ${ }^{+/ / K i} \mathrm{n}=8$

- RosaCreERT2 $2^{+/ K i} ;$ GFP Chimeras $\mathrm{n}=6$

- $B c l-x^{f / f t} ; G F P$ Chimeras $\mathrm{n}=6$

- $B c l-x^{f / f f l} ;$ RosaCreERT2 $2^{+/ K i} ;$ GFP Chimeras $\mathrm{n}=21$

H

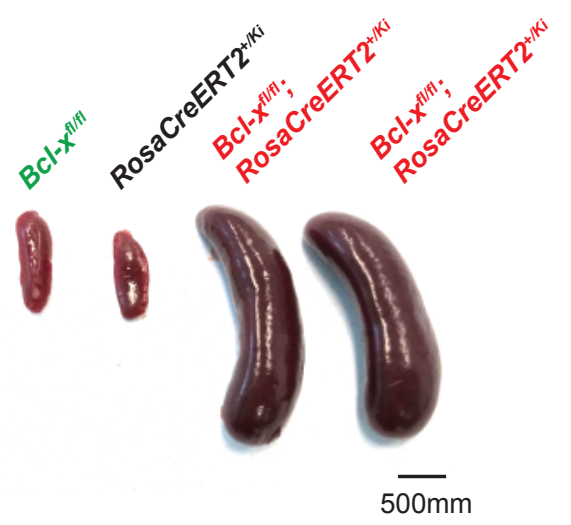

wt (age matched)

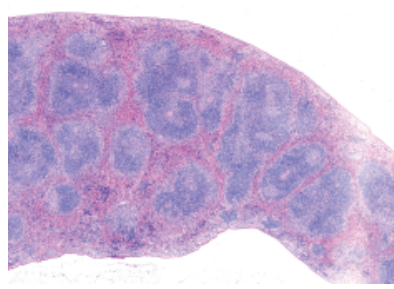

RosaCreERT2 ${ }^{+/ K i}$; GFP Chimera (>240 dpt)

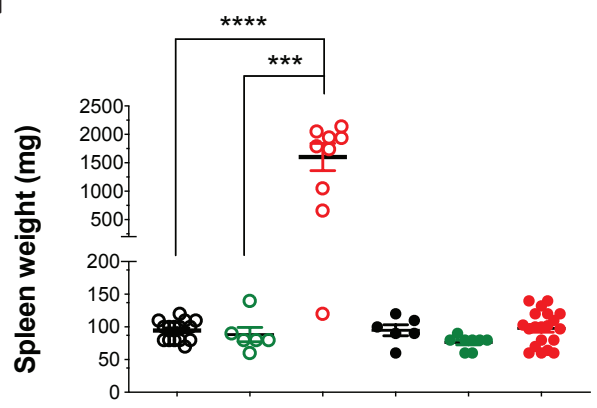

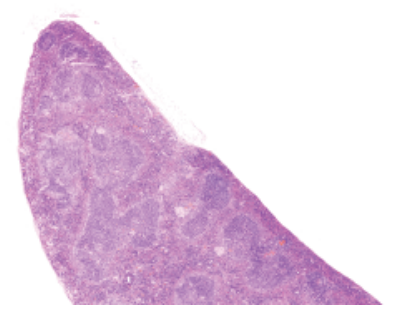

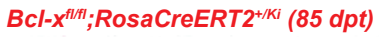

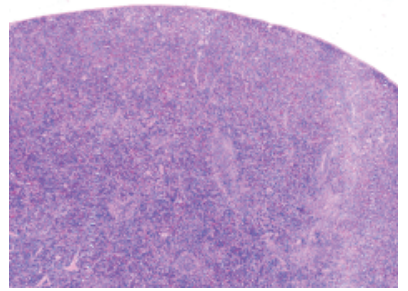

$B c l-x^{f / f f l} ; R o s a C r e E R T 2^{+/ / K i}$; GFP Chimera (114 dpt)

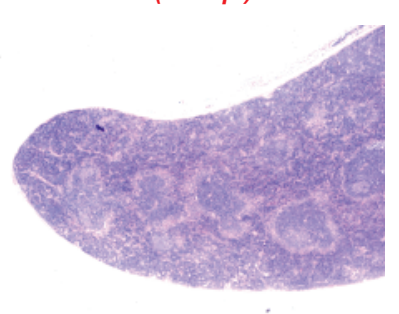


Figure 2: $\quad$ The combination of $\gamma$-radiation and inducible deletion of $B C L-X L$ neither causes inflammation, hematopoietic malignancy nor liver damage.

bioRxiv preprint doi: https://doi.org/10.1101/2020.04.28.055665; this version posted April 29, 2020. The copyright holder for this preprint (which was not certified by peer review) is the author/funder. All rights reserved. No

A

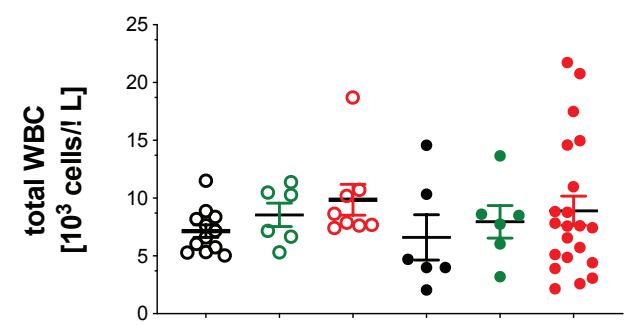

O RosaCreERT2 ${ }^{+/ K_{i}} \mathrm{n}=12$

O $B C l-x^{f / f t} \mathrm{n}=6$

O Bcl-x $x^{f / f t} ;$ RosaCreERT2 ${ }^{+/ / K i} \mathrm{n}=8$

- RosaCreERT2 $2^{+/ / i} ; G F P$-Chimera $\mathrm{n}=6$

- $B c l-x^{f f / t} ; G F P$-Chimera $\mathrm{n}=6$

- $B c l-x^{f / f t} ;$ RosaCreERT2 $2^{+/ K i} ;$ GFP-Chimera $n=21$

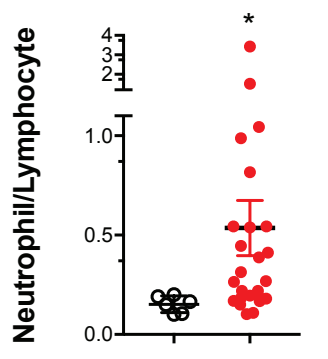

$\mathrm{NLR}=0.1368+/-0.0023$

$\mathrm{NLR}=0.5358+/-0.0151$

C

wt (aged 154d)

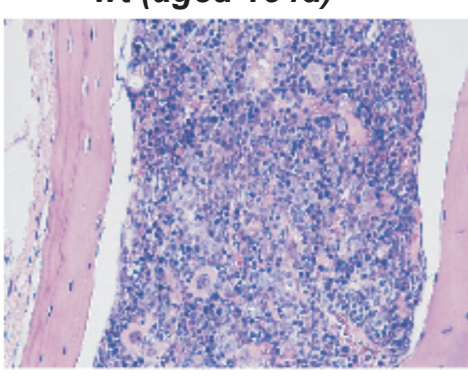

D
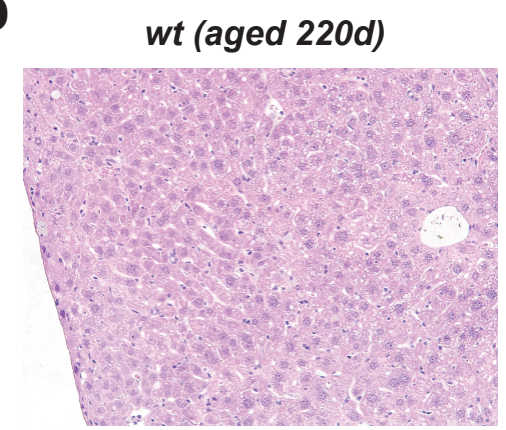

RosaCreERT2 ${ }^{+/ K i}$; GFP-Chimera (114 dpt)

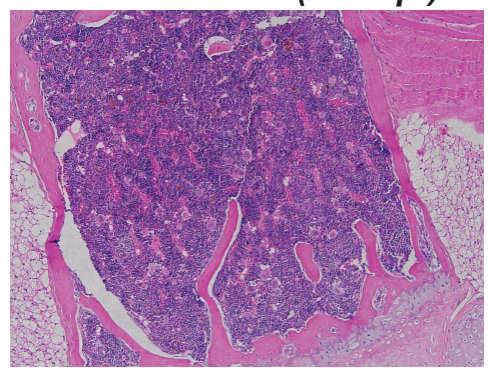

RosaCreERT2 ${ }^{+/ K i}$; GFP-Chimera (240 dpt)

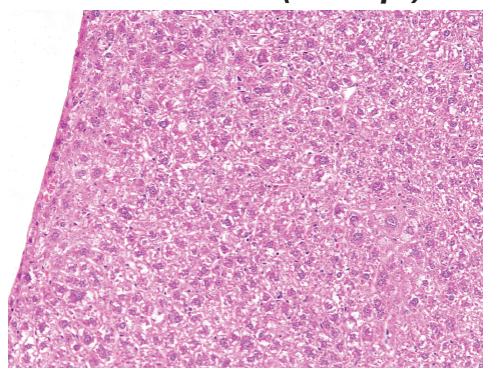

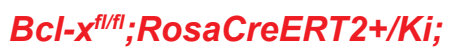
GFP-Chimera (114 dpt)

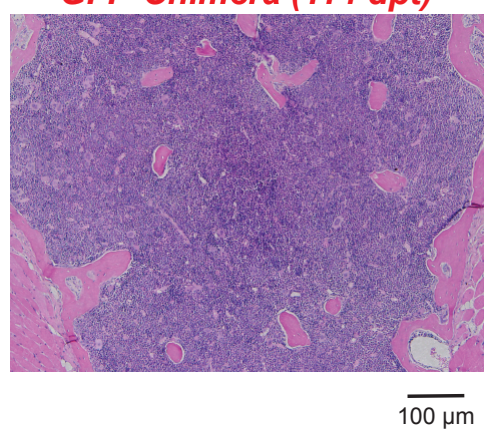

Bcl-X ${ }^{f / f l} ;$ RosaCreERT2 ${ }^{+/ K i}$; GFP-Chimera (71 dpt)

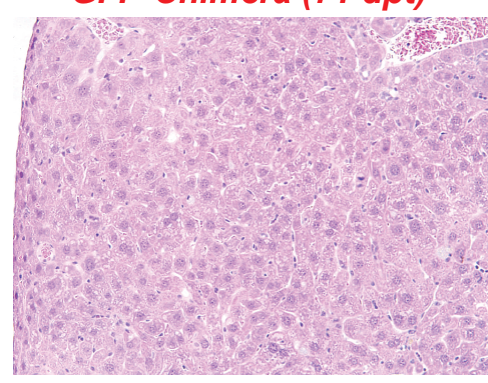

$\overline{100 \mu \mathrm{m}}$

트
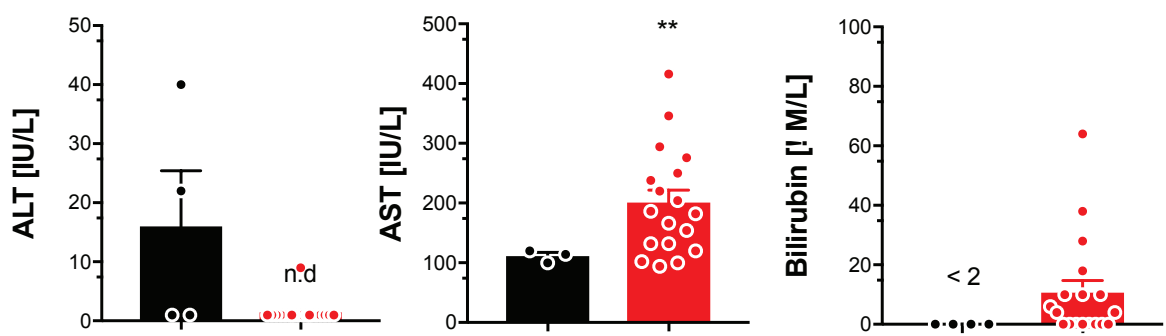

- RosaCreERT2 $2^{+/ k i}$. GFP-Chimeras $\mathrm{n}=4$

- $B C l-x^{f / f t} ;$ RosaCreERT2 $2^{+/ / K i}$; GFP-Chimeras $\mathrm{n}=18$ 
Figure 3: $\quad$ The combination of $\gamma$-radiation and inducible deletion of BCL-XL causes fatal kidney damage

$$
\begin{aligned}
& \text { bioRxiv preprint doi: https://doi.org/10.1101/2020.04.28.055665; this version posted April 29, 2020. The copyright holder for this preprint (which } \\
& \text { was not certified by peer reyiew) is the author/funder. All rights reserved. No reuse allowed without permission. }
\end{aligned}
$$

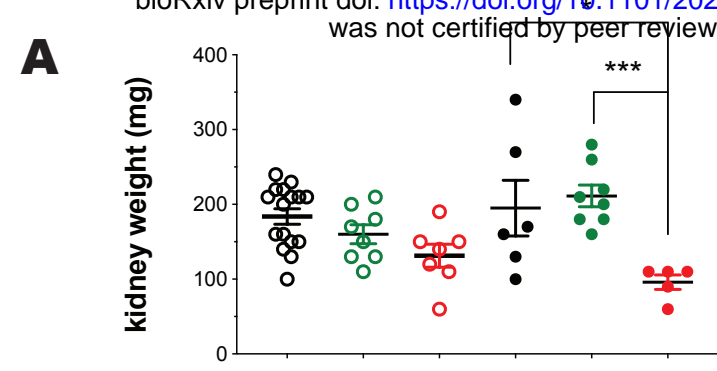

B

$\begin{array}{ll}\text { wt, } & \mathrm{Bcl}-\mathrm{x}^{f \mid f f} ; \\ \text { no treatment, } & \text { RosaCreERT2 } 2^{+/ K i} ; \\ \text { age matched } & \text { GFP-Chimera, } 88 \mathrm{dpt}\end{array}$

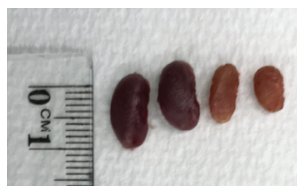

C

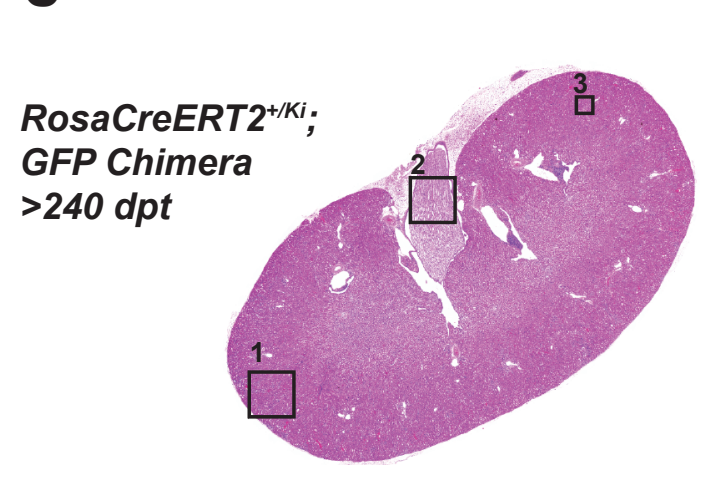

$B c /-x^{f / f I} ;$

RosaCreERT2 ${ }^{+/ K i}$; GFP Chimera $88 \mathrm{dpt}$

D

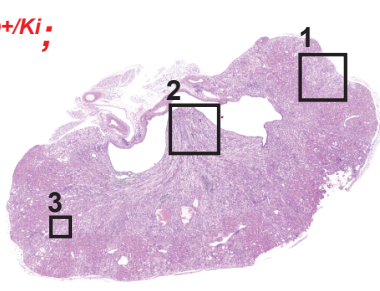

RosaCreERT2+/Ki; GFP Chimera, $88 d p t$

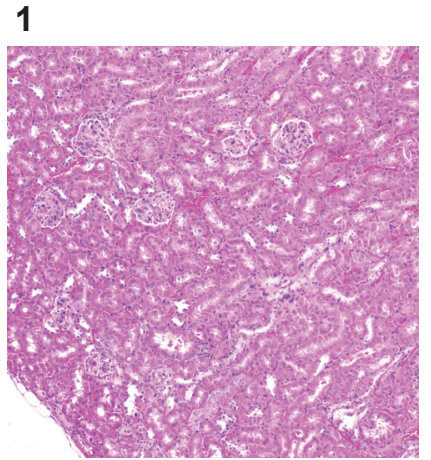

23

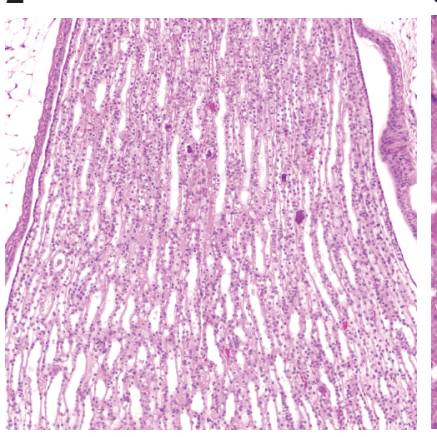

3

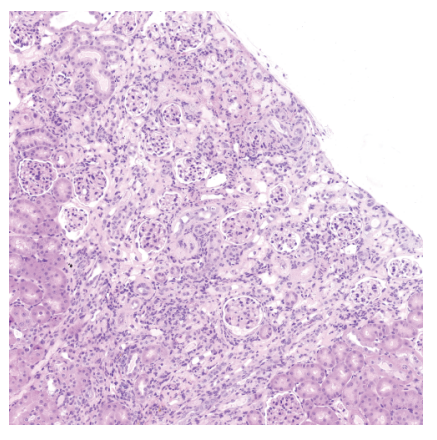

$100 \overline{\mu m}$

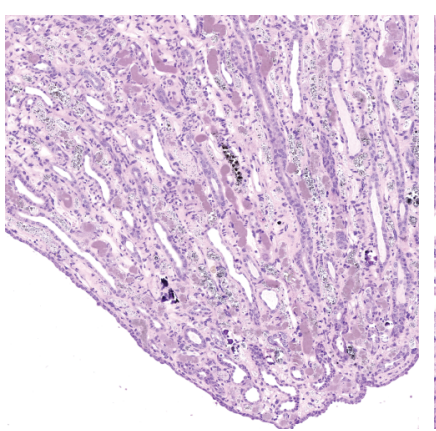

$10 \overline{\mu \mathrm{m}}$
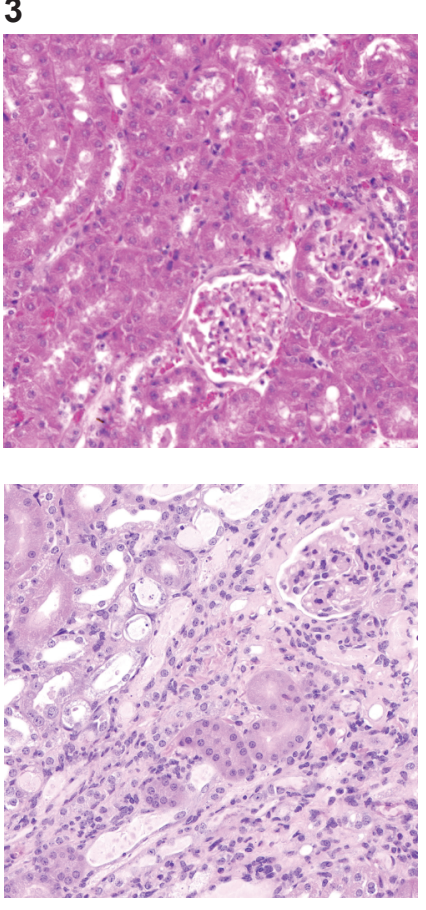

$00 \mu \mathrm{m}$

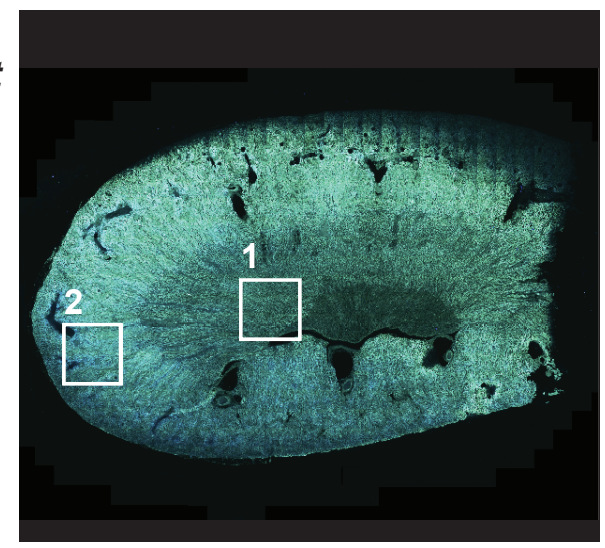

1

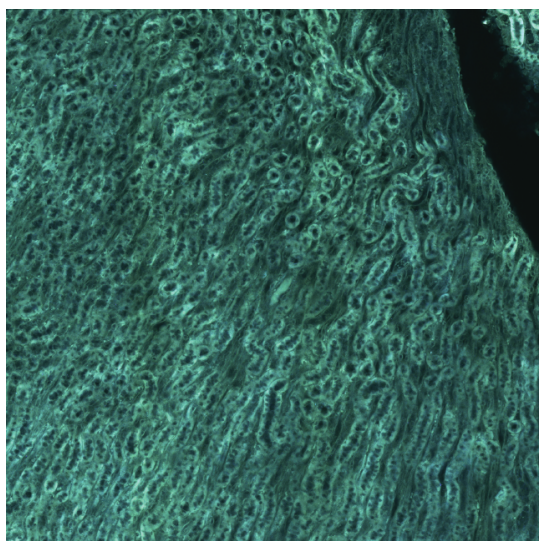

2
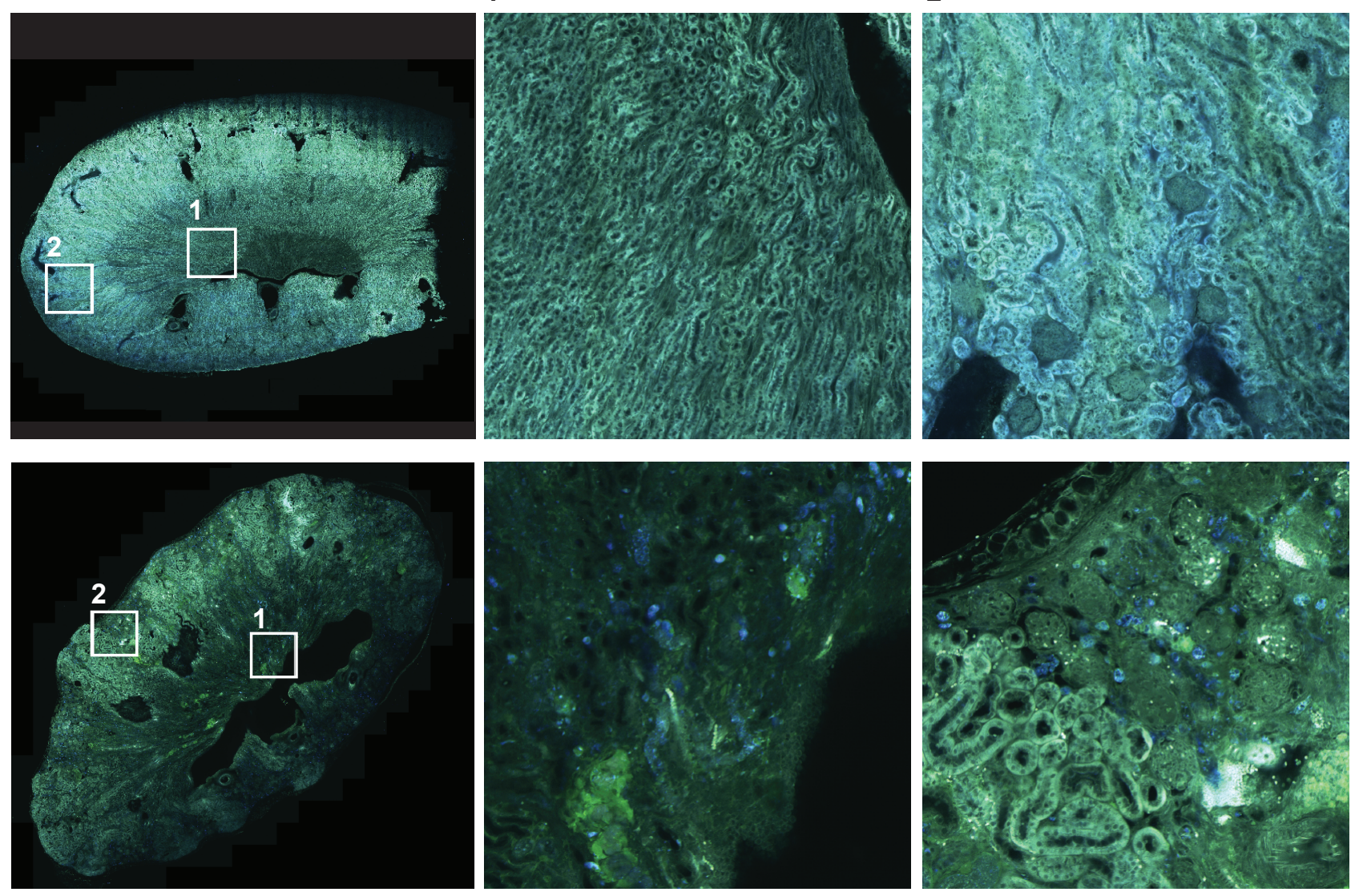

$\mathrm{Bcl}-\mathrm{x}^{\mathrm{fl} / \mathrm{f}}$

RosaCreERT2 ${ }^{+/ K i}$; GFP Chimera, $88 d p t$ 
Figure 4: The combination of $\gamma$-irradiation and inducible deletion of BCL-XL causes substantial apoptosis of various renal cell types.

bioRxiv preprint doi: https://doi.org/10.1101/2020.04.28.055665; this version posted April 29, 2020. The copyright holder for this preprint (which was not certified by peer review) is the author/funder. All rights reserved. No reuse allowed without permission.

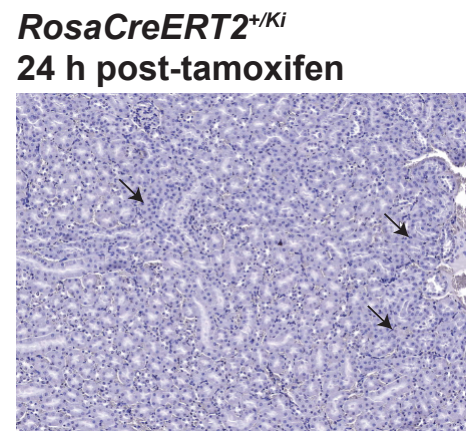

\section{RosaCreERT2 ${ }^{+/ K i}$ \\ $24 \mathrm{~h}$ post- $\gamma$-irradiation}

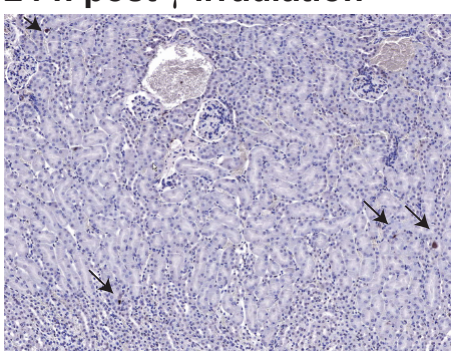

\section{$B C l-x^{f l f l} ; R o s a C r e E R T 2^{+/ K i}$}

$24 \mathrm{~h}$ post-tamoxifen

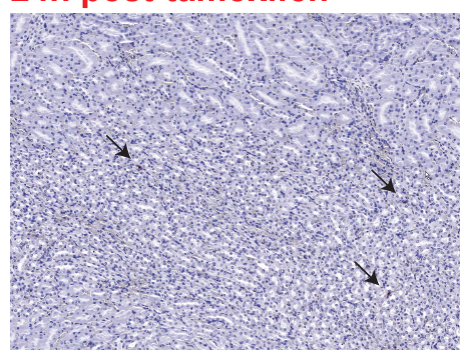

Bcl-X ${ }^{f \mid / f l} ; R$ RosaCreERT2
24h post- $\gamma$-irradiation

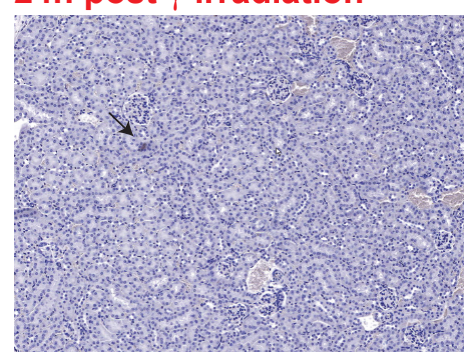

RosaCreERT2+/Ki

\section{GFP-Chimera}

$24 \mathrm{~h}$ post-tamoxifen

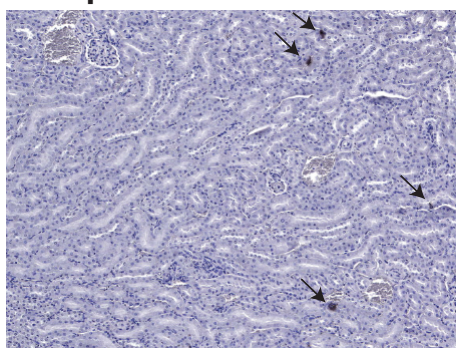
$B c /-x^{f / / f l} ;$ RosaCreERT2 ${ }^{+/ K i}$ GFP-Chimera
24h post-tamoxifen

RosaCreERT2+/Ki

GFP-Chimera

240 days post-tamoxifen

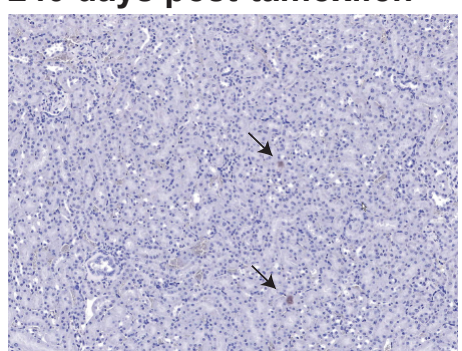

$\mathrm{Bcl}-\mathrm{X}^{\mathrm{fl} / \mathrm{fl} ;} ; \mathrm{RosaCreERT2}^{+/ \mathrm{Ki}}$

GFP-Chimera

114 days post-tamoxifen
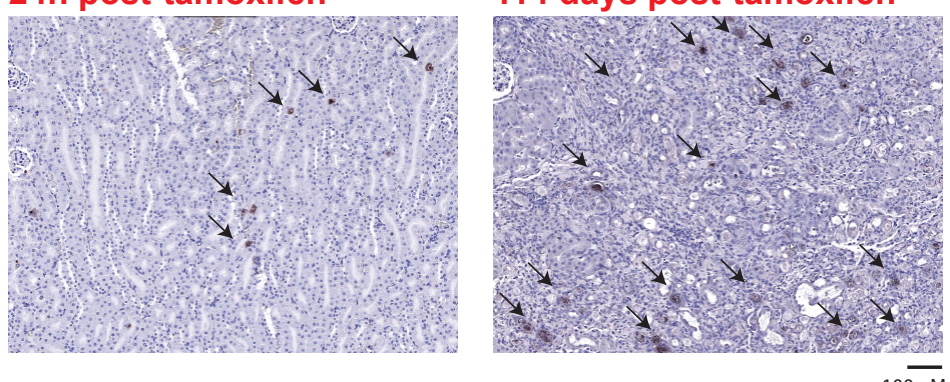

B

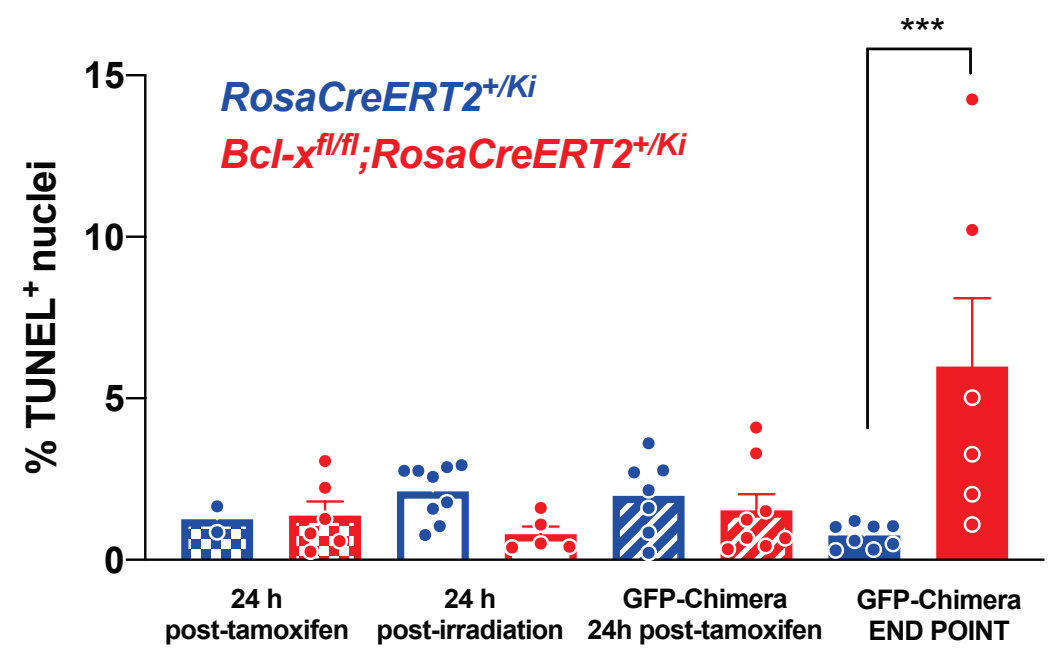


Figure 5: Concomitant loss of BIM or PUMA delays the fatal kidney disease caused by the combination of $\gamma$-irradiation and inducible deletion of BCL-XL

A bioRxiv preprint doi: https://doi.org/10,1101/2020.04.28.055665; this vension posted April 29 2020. The copyright holder for this preprint (which
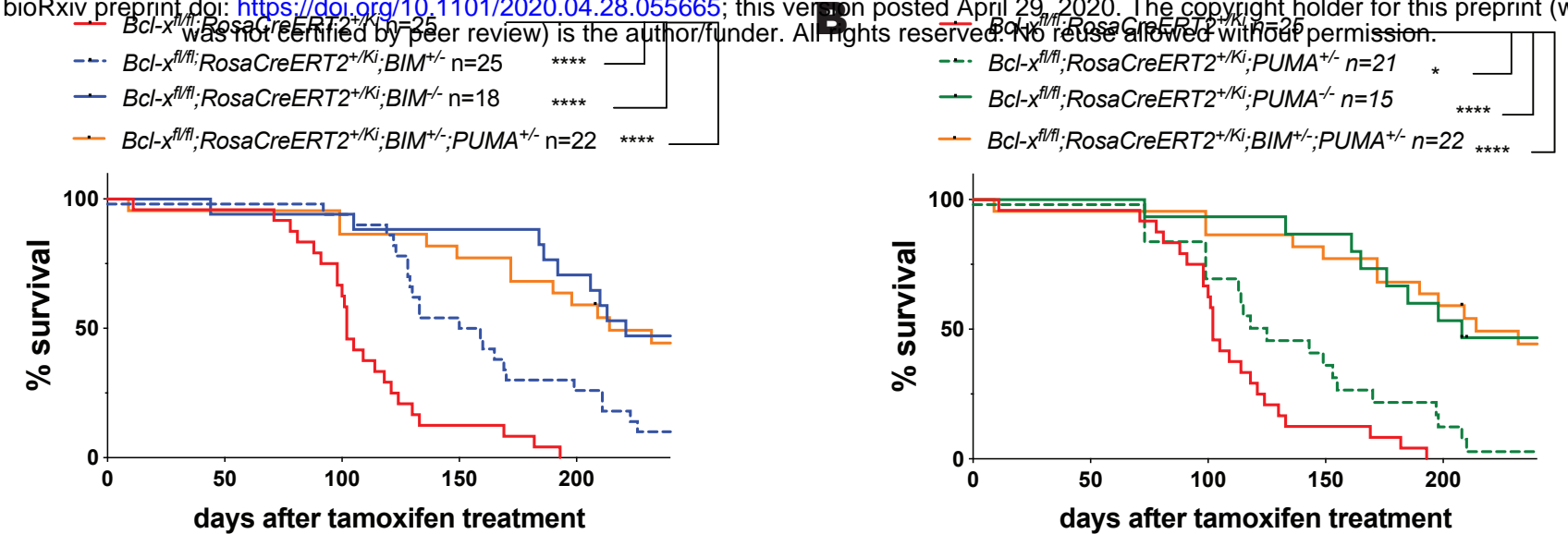

$\mathrm{BCl}-\mathrm{X}^{\mathrm{fl/fl}} ; \mathrm{Bim}^{-/ /} ; \mathrm{RosaCreERT2}{ }^{+/ / K i} ;$ GFP Chimera, $243 d p t$

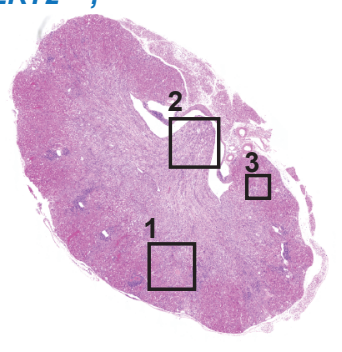

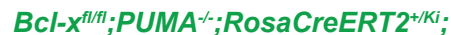

GFP Chimera, $281 d p t$

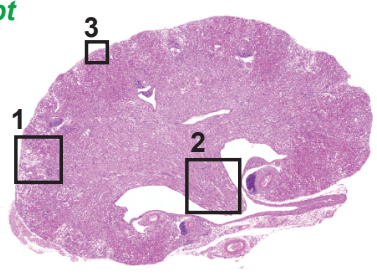

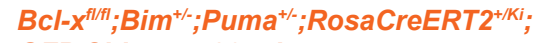
GFP Chimera, $304 d p t$

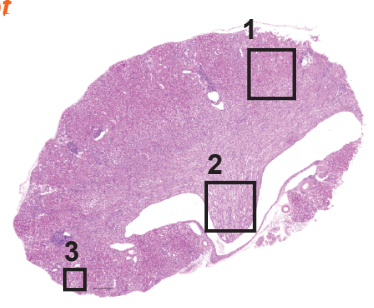

$1000 \mu \mathrm{m}$

- RosaCreERT2 $2^{+/ K i} ;$ GFP-Chimera $n=6$

- $B c l-x^{f / / f l} ;$ RosaCreERT2 ${ }^{+/ K i} ; G F P$-Chimera $n=21$

- $\mathrm{BCl}-\mathrm{x}^{\mathrm{fl} / \mathrm{fl} ;} ;$ RosaCreERT2+//Ki$; \mathrm{Bim}^{+/-; G F P-C h i m e r a ~} n=20$

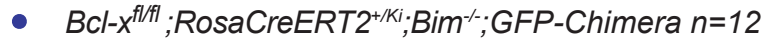

D

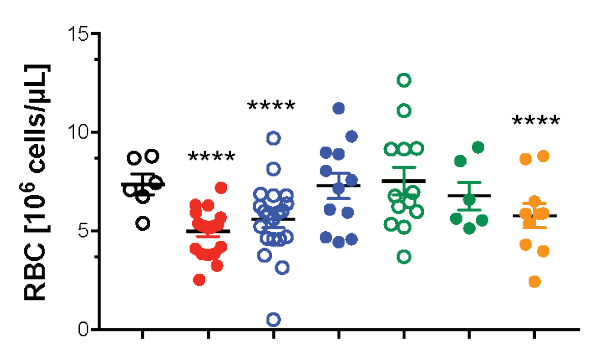

1

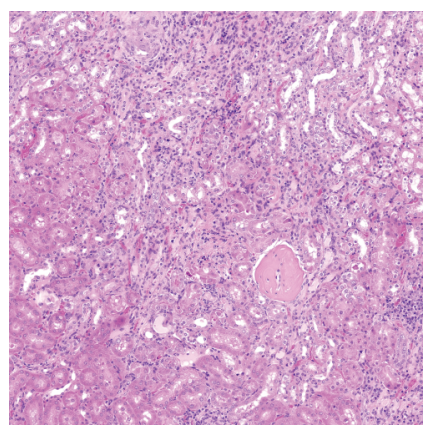

2
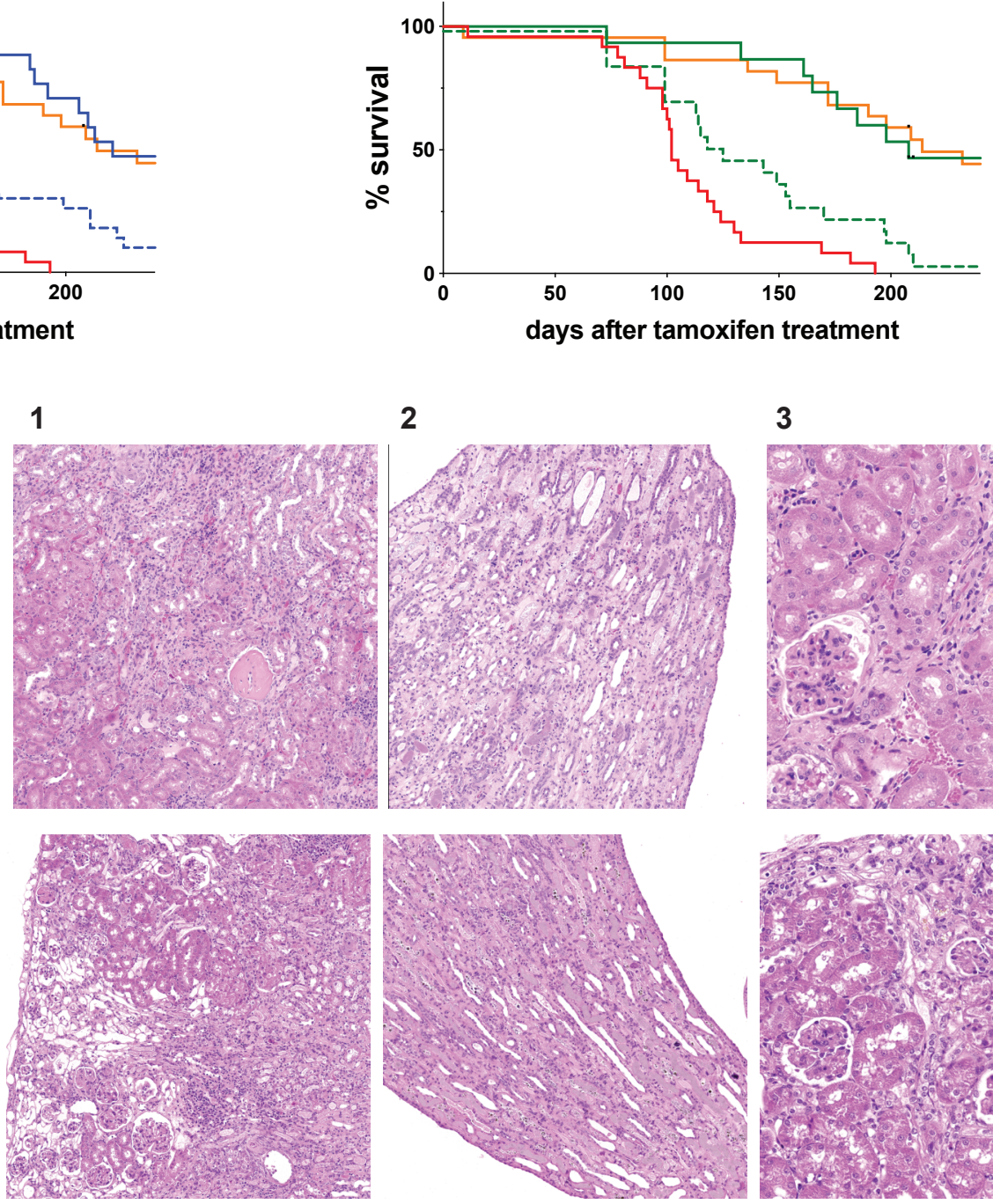

days after tamoxifen treatment

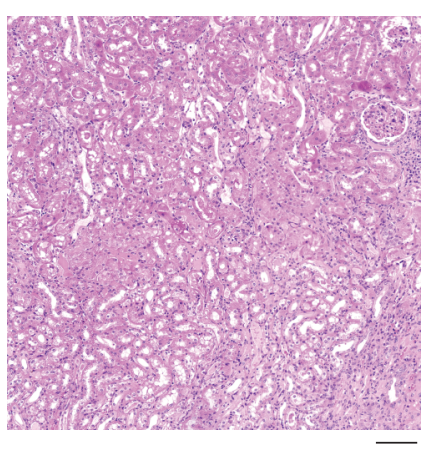

$100 \mu \mathrm{m}$

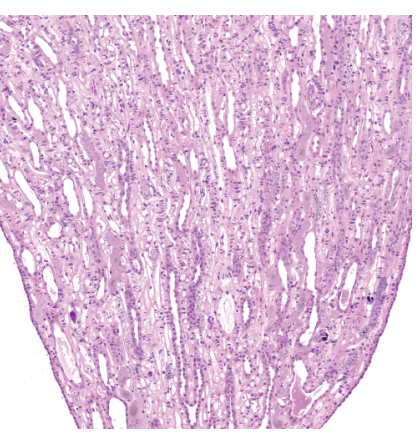

$10 \overline{\mu \mathrm{m}}$
3
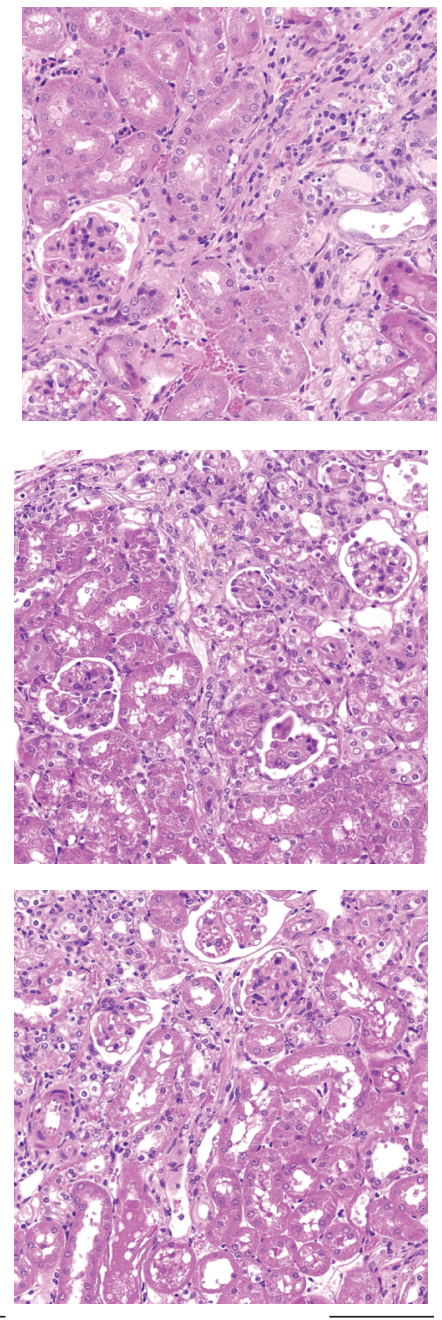

$100 \mu \mathrm{m}$

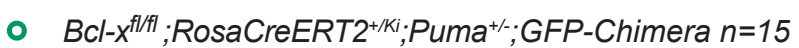

- $B c l-x^{f l / f l} ;$ RosaCreERT2 $2^{+/ / i} ;$ Puma $^{-/ ;}$GFP-Chimera $n=10$

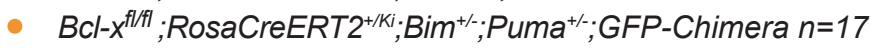

$\mathbf{E}$

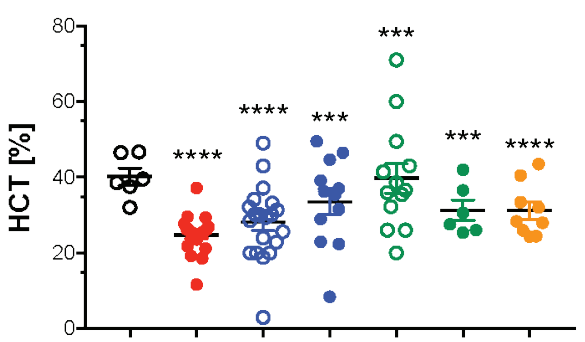

$\mathbf{F}$

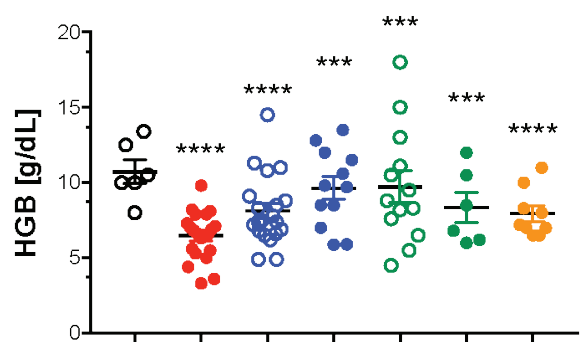


Figure 6: Pharmacological inhibition of $B C L-X L$ in combination with DNA damage-inducing chemotherapeutics or $\gamma$-irradiation at clinically relevant doses is tolerated in mice

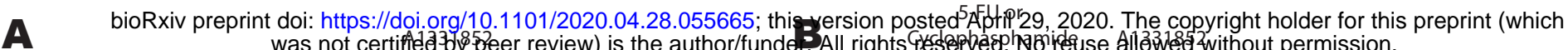

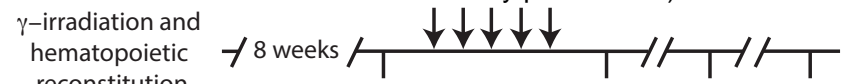
reconstitution $\quad$ pre-treatment d6pt d100pt $>$ d240pt blood analysis
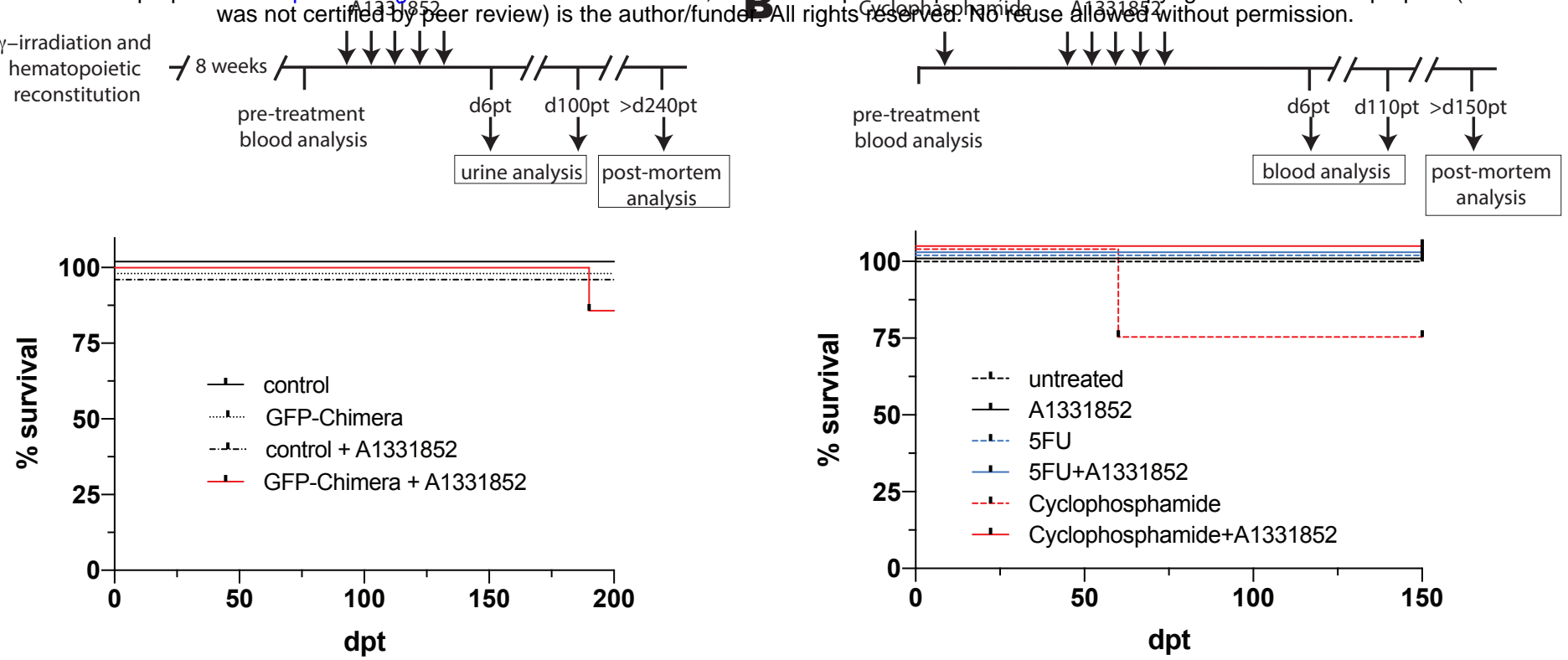

C

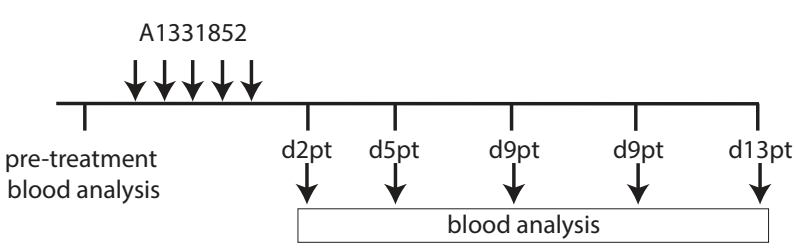

D
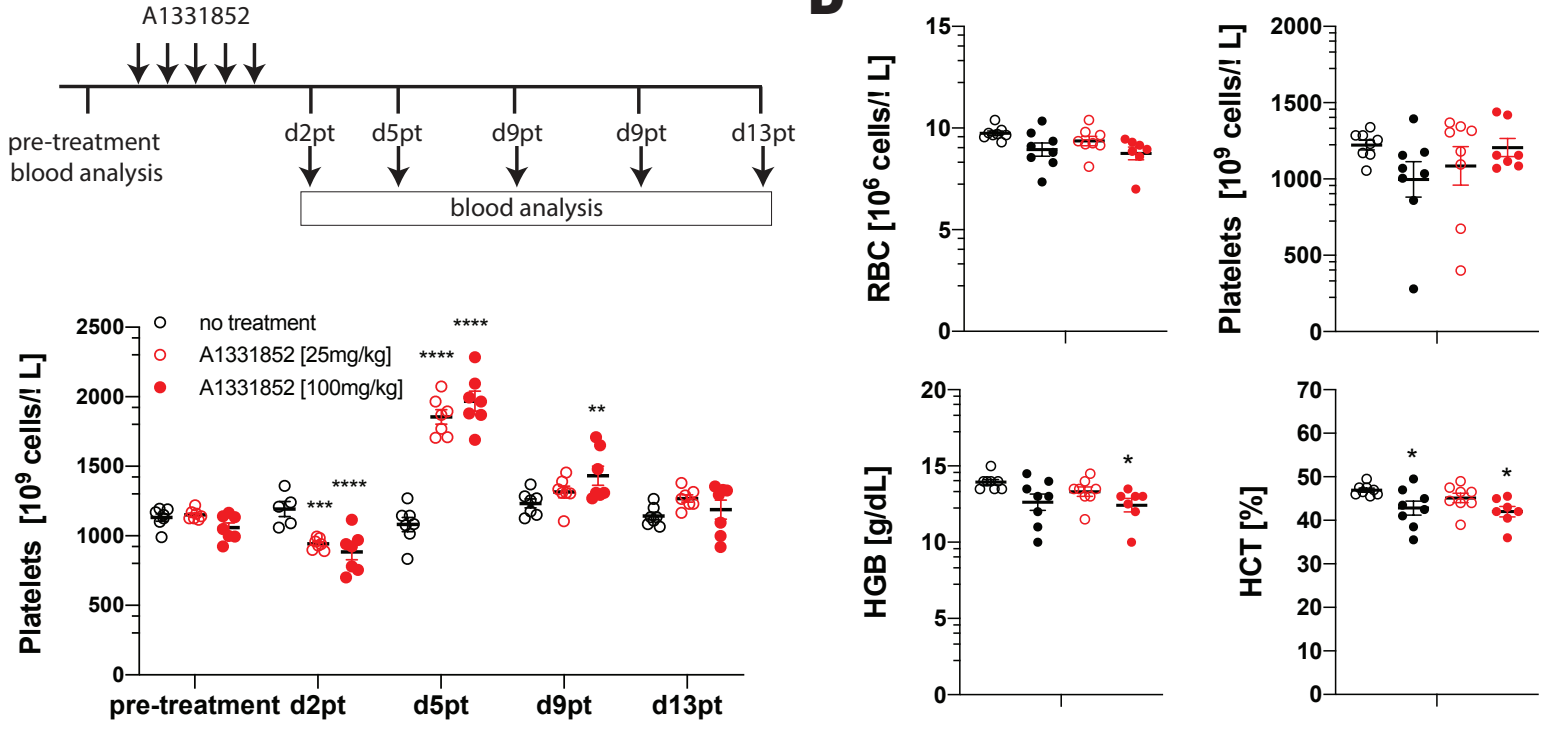

- ctrl

- GFP-Chimera

- ctrl + A1331852

- GFP-Chimera + A1331852
$\mathbf{E}$
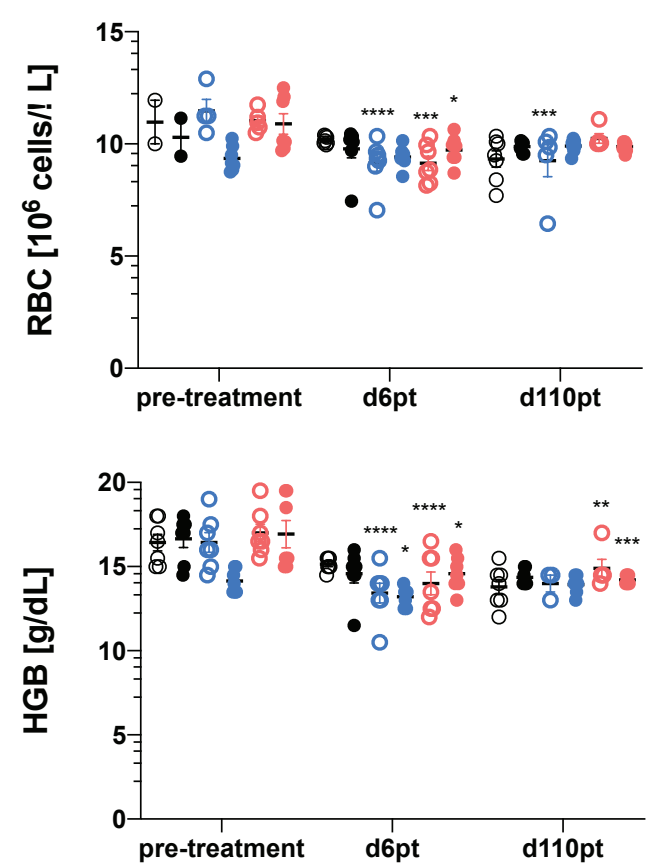

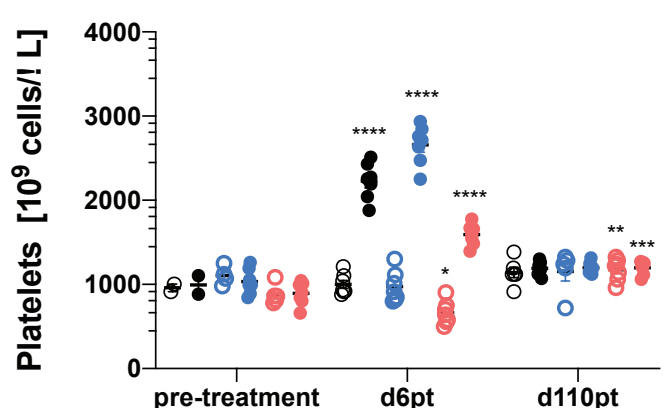

- untreated

- A1331852

- 5-FU

- 5-FU + A1331852

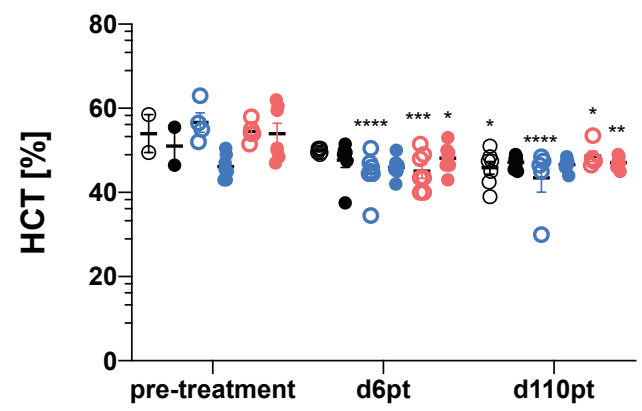

- Cyclophosphamide

- Cyclophosphamide + A1331852 
Figure 7: $\quad$ Pharmacological inhibition of BCL-XL in combination with DNA damage at clinically relevant doses does not impact on kidney function

A bioRxiv preprint doi: https://doi.org/10.1101/2020.04.28.055665; this versio 3 osted April 29, 2020. The copyright holder for this preprint (which was nुot certified by peer review) is the author/funder. All rights 258 served. No reuse allowed without permission.
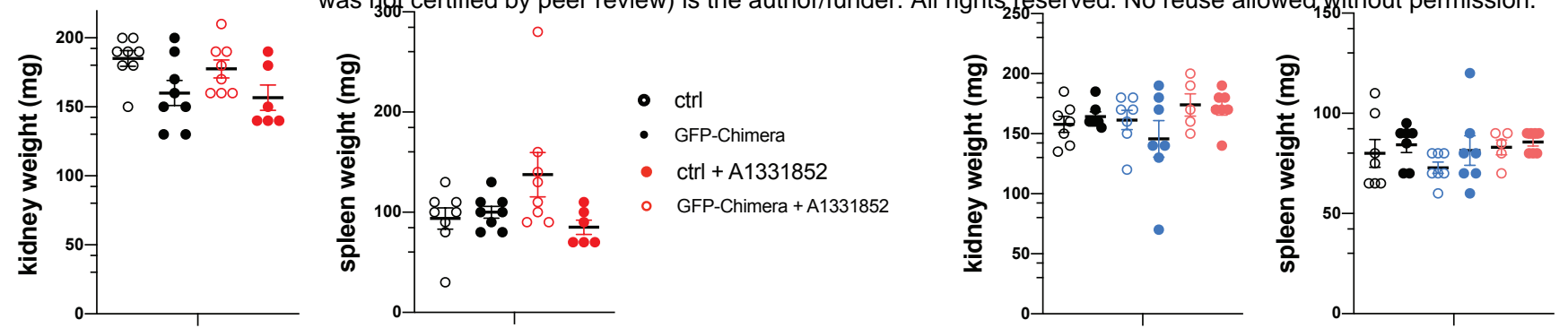

- untreated

- A1331852

- 5-FU

5-FU + A1331852

- Cyclophosphamide

- Cyclophosphamide + A1331852

C

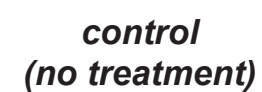

control
+ A1331852

GFP-Chimera

GFP-Chimera A1331852
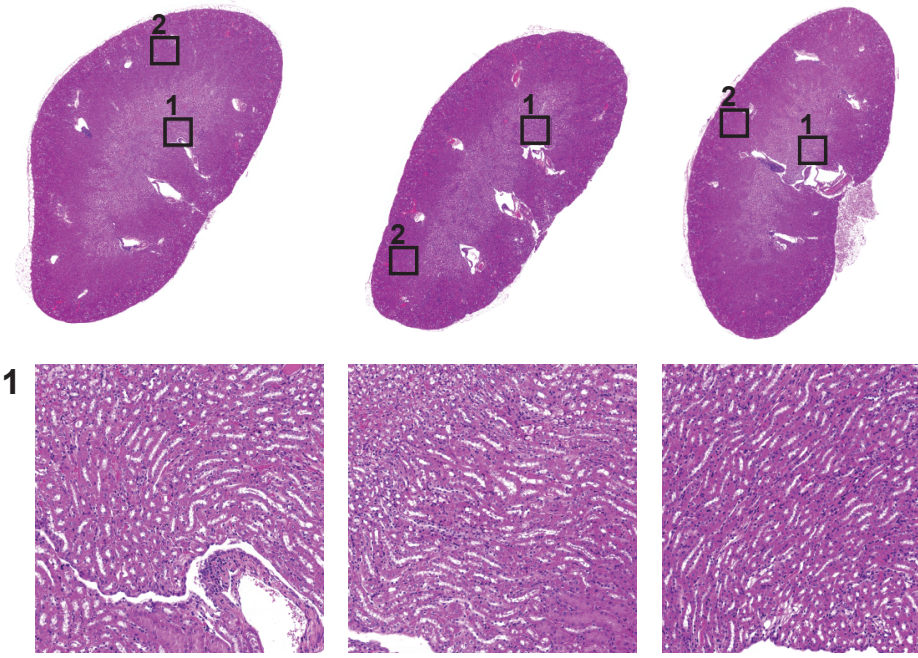

2
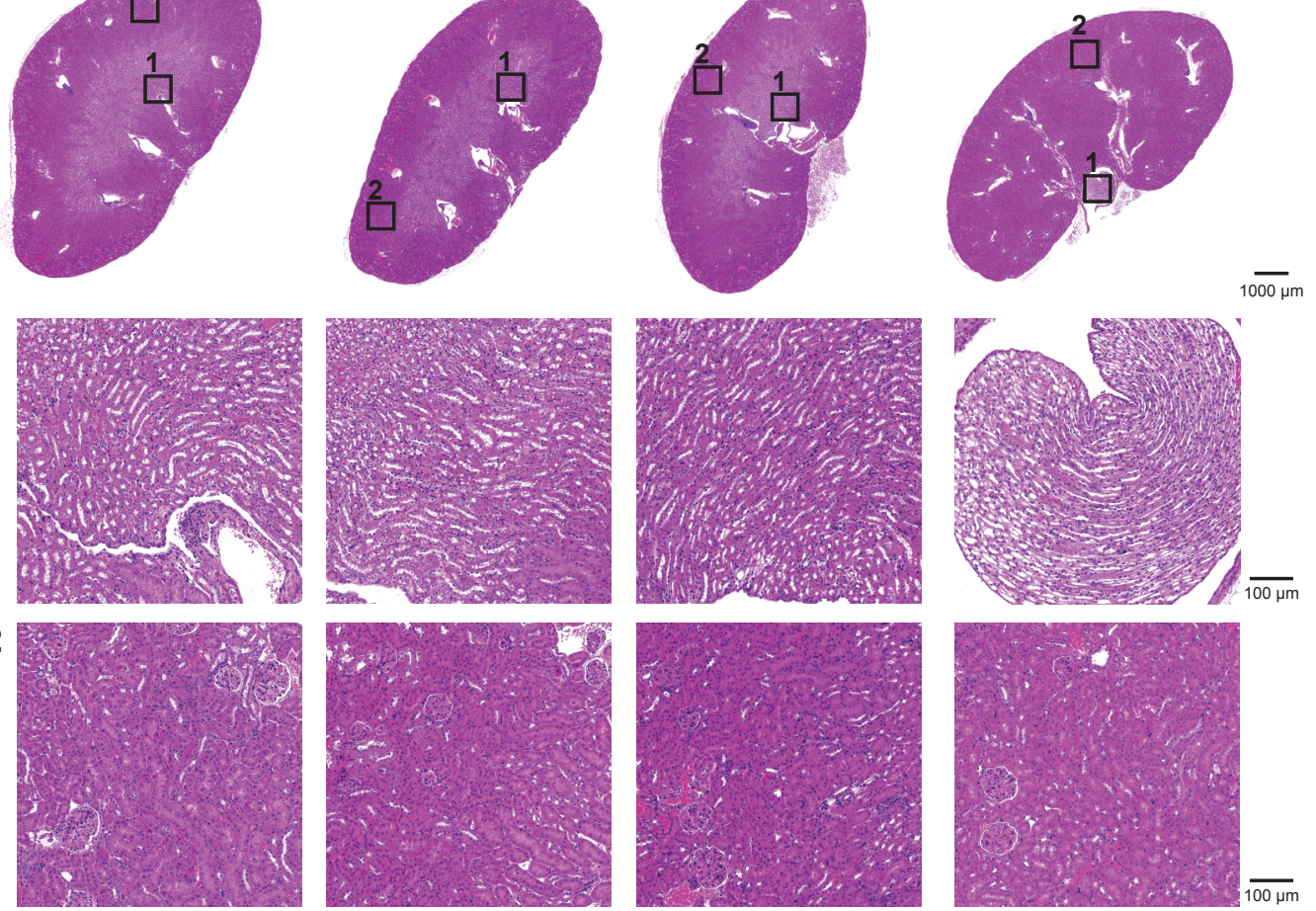

D

\section{control (no treatment)}

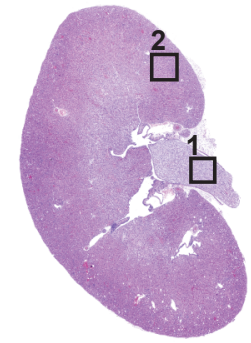

1

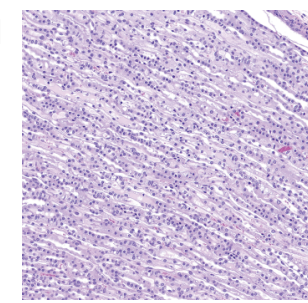

2

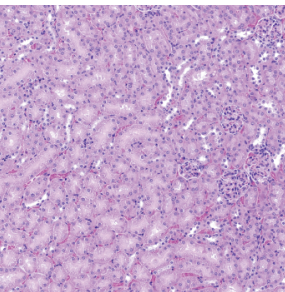

A1331852
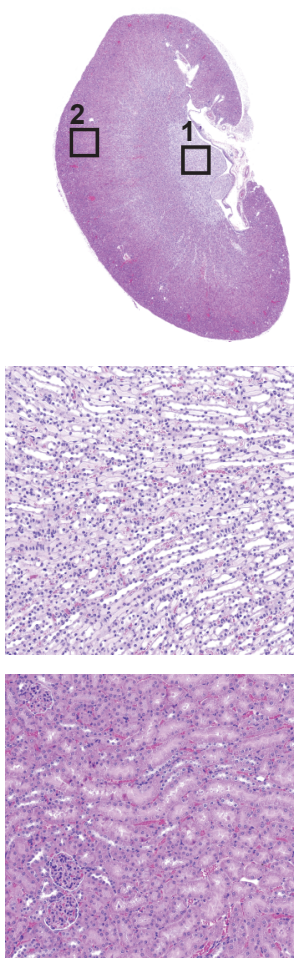

$5-F U$
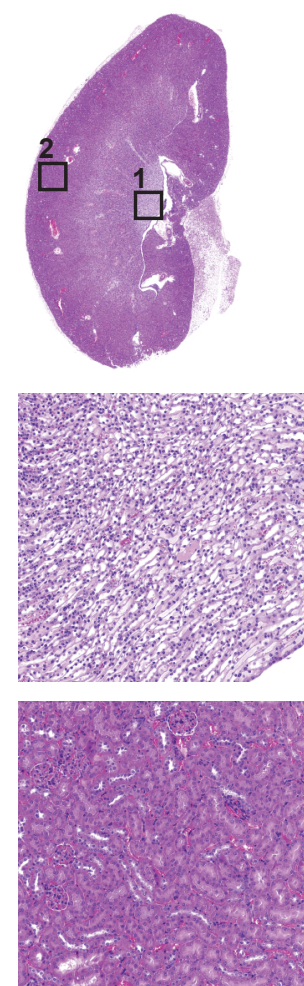

$5-\mathrm{FU}+$ A1331852
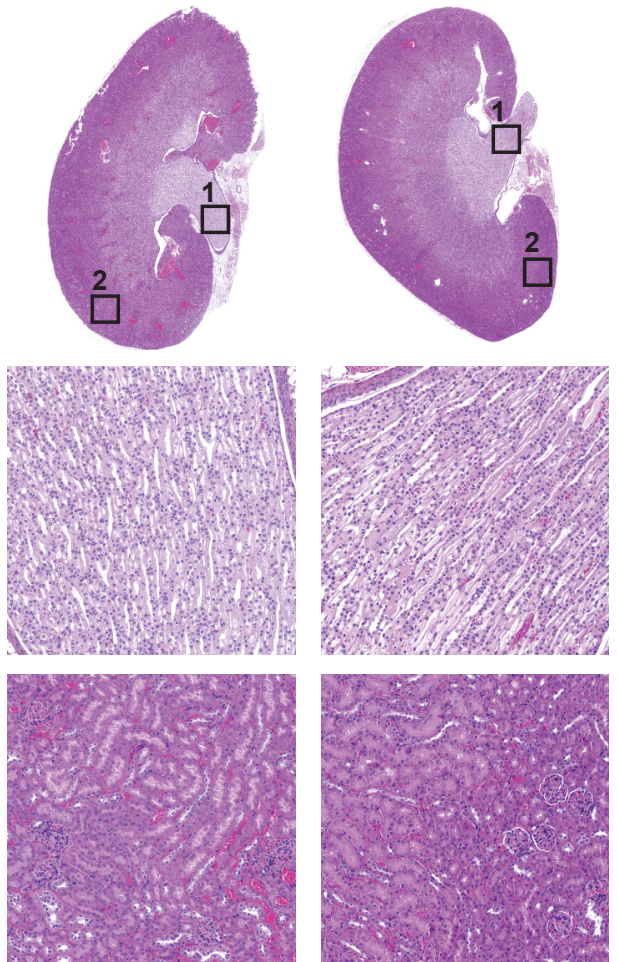

Cyclophosphamide

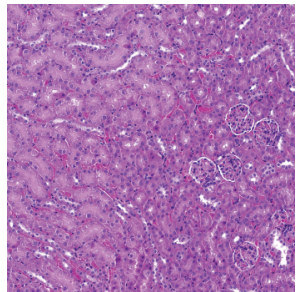

Cyclophosphamide + A1331852
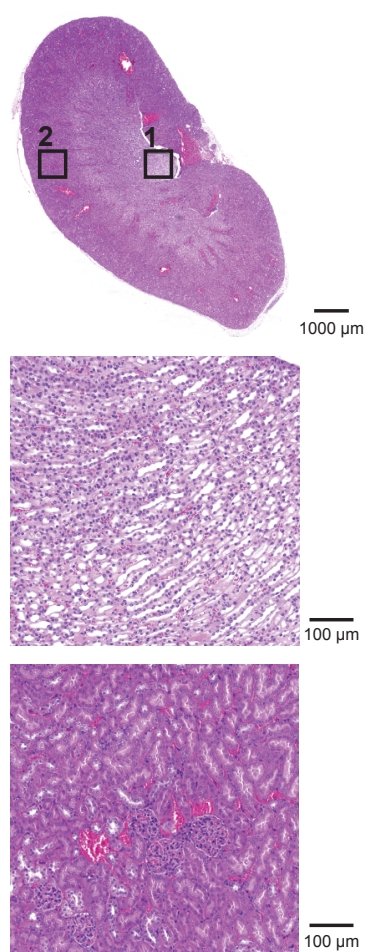